\title{
PERSISTENCE OF MONOPOLY, INNOVATION, AND R\&D SPILLOVERS: STATIC VERSUS DYNAMIC ANALYSIS
}

\author{
Eugen Kováč \\ Viatcheslav Vinogradov \\ Krešimir Žigič
}
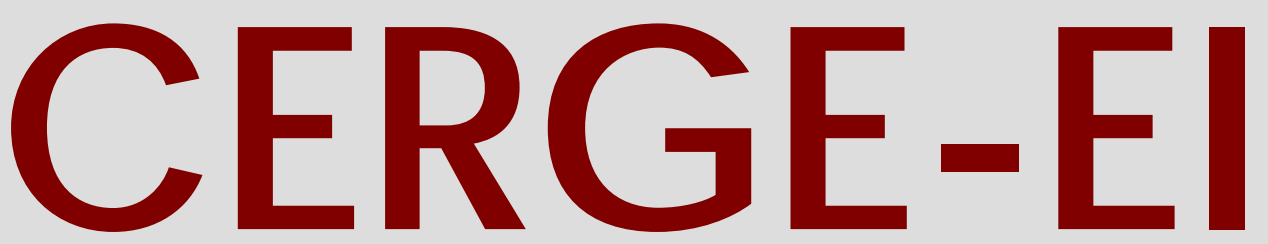

Charles University CenterforEconomic Research and Graduate Education Academy of Sciences of the Czech Republic Ec onomic s Institute 


\title{
Working Paper Series 316 (ISSN 1211-3298)
}

\section{Persistence of Monopoly, Innovation, and R\&D Spillovers: Static versus Dynamic Analysis}

\author{
Eugen Kováč \\ Viatcheslav Vinogradov \\ Krešimir Žigič
}

CERGE-EI

Prague, January 2007 
ISBN 978-80-7343-113-6 (Univerzita Karlova. Centrum pro ekonomický výzkum a doktorské studium)

ISBN 978-80-7344-102-9 (Národohospodářský ústav AV ČR, v.v.i.) 


\title{
Persistence of Monopoly, Innovation, and R\&D Spillovers: Static versus Dynamic Analysis
}

\author{
Eugen KováČ ${ }^{\mathrm{a}, \mathrm{c}}$ \\ ViATCHESLAV ViNOGRADOV ${ }^{\mathrm{a}, \mathrm{b}}$ \\ KREŠIMIR ŽIGIČ ${ }^{\mathrm{a}}$
}

\begin{abstract}
We build a dynamic duopoly model that accounts for the empirical observation of monopoly persistence in the long run. More specifically, we analyze the conditions under which it is optimal for the market leader in an initially duopoly setup to undertake pre-emptive R\&D investment ("strategic predation") that eventually leads to the exit of the follower firm. The follower is assumed to benefit from the innovative activities of the leader through $R \& D$ spillovers. The novel feature of our approach is that we introduce an explicit dynamic model and contrast it with its static counterpart. Contrary to the predictions of the static model, strategic predation that leads to the persistence of monopoly is in general the optimal strategy to pursue in a dynamic framework when spillovers are not large.

V tomto článku konstruujeme dynamický model duopolu, který souhlasí s empirickým pozorováním stálosti monopolu v dlouhodobém horizontu. Konkrétně analyzujeme podmínky, v kterých je pro vůdce trhu s původně duopolním uspořádaním optimální preventivně investovat do výzkumu a rozvoje (dále $R \& D$ - research \& development), což má za následek odchod druhé firmy (následovníka) z trhu (strategie "strategického predátorství"). U následovníka se předpokládá, že získává výhodu z inovačních aktivit vůdce přes R\&D spillover. Náš přístup je novátorský v tom, že zavádíme explicitní dynamický model a porovnáváme ho s jeho statickým protějškem. V protikladu s predikcemi statického modelu, strategické predátorství vedoucí $\mathrm{k}$ stálosti monopolu je obecně optimální strategií, která by měla být v dynamickém konceptu uplatňována pokud spillover není př́liš rozsáhlý.
\end{abstract}

Keywords: dynamic duopoly, R\&D spillovers, persistence of monopoly, strategic predation, accommodation

JEL Classification: L12, L13, L41

${ }^{a}$ CERGE-EI, a joint workplace of the Center for Economic Research and Graduate Education at Charles University in Prague, and the Economics Institute of the Czech Academy of Sciences. The authors are grateful to J. Engwerda, P. Katusčak, S. Slobodyan, participants of the CEF-2006 conference in Limassol and the EEA/EESM-2006 meeting in Vienna for helpful comments and suggestions, to L. Straková for English editing assistance, and to Z. Budinová and V. Strohush for research assistance on earlier drafts of the paper. The standard caveat applies.

${ }^{\mathrm{b}}$ Corresponding author can be contacted via e-mail at viatcheslav .vinogradov@cerge-ei.cz, or via post at CERGE-EI, P.O. Box 882, Politických vězňů 7, 11121 Prague 1, Czech Republic, phone (+420) 224005 234, fax (+420) 224227143.

${ }^{\mathrm{c}}$ Department of Economics, University of Bonn, Germany. 


\section{Introduction}

Is monopoly an environment conducive to innovation? Is there persistence of monopoly, or is there a change in the identity of the innovating firm ("leapfrogging")? These kinds of questions are not new among economists, but recently they seem to have been rekindled. In a recent issue of The Economist (2004), the authors of the already celebrated column "Economics Focus" in their provocatively entitled article "Slackers or Pace-Setters: Monopolies may have more incentives to innovate than economists have thought" claimed that monopolies may have a far more prominent role in generating innovation than previously thought. The authors further expressed doubts about the prevailing economic theory according to which "a monopolist should have far less incentives to invest in creating innovations than a firm in a competitive environment." Apparently, there is some controversy regarding the role of market power and monopolies in creating innovations, and the key to resolving it lies in the underlying incentives to engage in innovation. Recent empirical evidence seems to support these Schumpeterian allegations from The Economist: there is a positive relationship between market power and intensity of innovation (see, for instance, Blundell et al., 1999; Carlin et al.; 2004, Aghion and Griffith, 2004). Commenting on this empirical evidence, Etro (2004) stated that it "is consistent with pre-emptive R\&D investment by the leaders." As a consequence of such strategic behavior, there may be only one firm at the end of the day, but this firm would display far more competitive behavior than the standard monopolist; it would generate a higher flow of $\mathrm{R} \& \mathrm{D}$, charge a lower price, and produce more.

There are many real-world examples of monopolistic or dominant firms that invest more in innovation and $R \& D$ than their rivals (see Etro, 2004), and that survive over a long period of time. AT\&T, a giant American telecommunications company publicly listed on the New York Stock Exchange under the ticker symbol T, is a good case in point. Founded in 1885, the company is one of the largest telephone companies and cable television operators in the world. AT\&T provides voice, video, data, and Internet telecommunications services to businesses, consumers, and government agencies. After becoming the first long-distance telephone network in the US, AT\&T made huge investments in research and development. As a result, the company obtained near monopoly power on long-distance phone services. Heavy investments in $\mathrm{R} \& \mathrm{D}$ together with aggressive behavior on the market allowed AT\&T to acquire crucial inventions and to spread its near monopoly power to other markets. The company both bought patents for significant innovations ${ }^{1}$ and undertook

\footnotetext{
${ }^{1}$ For instance, during the early 1920s, AT\&T bought Lee De Forest's patents on the "audion", the first triode vacuum tube, which let it enter the radio business.
} 
innovations itself ${ }^{2}$. Only after a suit against AT\&T in 1982 followed by the breakup of the company into several local independent units called "Baby Bells" in 1984, did the US telephone industry become competitive, with other companies entering the market. And yet, although it lost part of its market power on long-distance telephone services, the company has continued its aggressive investments in R\&D. In 2004, AT\&T introduced a new technology allowed businesses to securely run their private networks without interruption on AT\&T's leading global Internet Protocol network. This move assuredly keeps the company a leader in IP networking. In the words of corporate promoters, "backed by the research and development capabilities of AT\&T labs, the company is a global leader in local, long distance, Internet and transaction-based voice and data services."

The above observations on the relation between innovation, leadership, and market power motivate our paper in that we aim to describe and analyze a particular setup in which the persistence of monopoly can arise in the long run. More specifically, we study the situation in which the market leader undertakes pre-emptive R\&D investment (or, in our words, adopts "strategic predation"), that eventually leads to the exit of the follower firm and/or prevents or limits the entry of new firms, and we contrast this situation with one in which the leader (within the same setup) "accommodates" the follower, that is, co-exists with the follower in a duopoly market structure. This comparison will enable us to study both positive aspects (for instance, which strategy yields higher R\&D intensity or R\&D stock) of the two main strategies - accommodation and strategic predation, and normative aspects (social welfare implications) of the two resulting market structures: duopoly versus (constrained or unconstrained) monopoly. The latter aspect, as we will see, carries important policy implications.

The novel feature of our approach is that we utilize an explicit dynamic model and contrast it with its static (or quasi-dynamic) counterpart. This comparison can be considered as the topic per se of our paper. Since strategic innovations are inherently dynamic phenomena, we argue that a suitable model aimed at capturing both accommodating and pre-emptive or predatory behavior of the dominant firm should be explicitly dynamic. Furthermore, to emphasize the role of the leader we assume that the leading firm is the only one that invests in innovation, while the follower imitates through $R \& D$ spillovers. The rationale for introducing spillovers stems from the fact that innovations, in general, are subject to R\&D spillovers for which the recipients need to have the so-called "absorptive capacity," that is, the "ability to identify, assimilate, and exploit knowledge from the environment and

\footnotetext{
${ }^{2}$ Notably, the first commercial communications satellite, Telstar I, was commissioned by AT\&T in 1962 .
} 
to apply it to commercial ends" (Cohen and Leventhal, 1989 and 1990). ${ }^{3}$ The importance of R\&D spillovers, imitations, and their economic implications seems to be well and broadly documented both in the theoretical and empirical literature (see, for instance, Griliches, 1992). However, most of the theoretical models are static in nature, and focus on the accommodation strategies. That is, strategic predation is simply ignored or precluded by assumptions (so that it is never optimal). In such situations unilateral R\&D spillovers create disincentives to invest in $R \& D$ and, consequently, hamper innovations. However, as we will see, in most cases in which strategic predation is optimal, the economic implication of $R \& D$ spillovers is exactly the opposite. They enhance the incentive to invest in R\&D.

A static (or quasi-dynamic) simple two-stage duopoly model will serve as a benchmark for our subsequent dynamic analysis. This should come as no surprise since the concept of two-stage (or $n$-stage) competition used to be a standard tool to tackle the above-mentioned types of strategic interactions. The concept of twostage competition concentrates on identifying "strategic effects" that influence firstperiod behavior and aims to characterize the resulting strategic rivalry. It has been proven successful in that the same strategic principles (e.g., "overinvestment" or "underinvestment") apply in many economic environments, and the comparative static results from static oligopoly theory can be used to provide information about strategic behavior (see Fudenberg and Tirole, 1984; Tirole, 1990; Shapiro, 1989; and Etro, 2004). However, such a concept relies on an artificial time structure, since the final (i.e., second or $n$-th) period is essentially one of static oligopoly (see Shapiro, 1989). From the perspective of the full-fledged dynamic model, it gives at best the "steady state values" of the true underlying dynamic game. Thus, it is lacking the explicit motion of the strategic variables over time and its accompanying comparative dynamics. More importantly, the set of strategies available to firms may be richer than in the corresponding static model. Moreover, the dynamic adjustment process is neglected in $n$-stage competition games.

In order to contrast the standard static two-stage competition approach with its dynamic counterpart, we first construct a specific two-stage game and then build its explicit dynamic version. More specifically, the benchmark model is a two-stage asymmetric duopoly game in which one firm (Firm 1) has a strategic advantage in the form of prior (first-stage) investment in $\mathrm{R} \& \mathrm{D}$ that leads to a unit cost decrease, while the second firm benefits from $R \& D$ spillovers. In the second stage the two firms compete in quantities. Thus both firms are assumed to be initially sustainable

\footnotetext{
${ }^{3}$ For an alternative approach that focuses on the incumbent's absorptive capacity see Wiethaus (2005). Under certain plausible conditions, Wiethaus (2005) demonstrates that a monopolist is able to retain its persistence by strategically investing in excess absorptive capacity.
} 
in the market. We then construct an explicit dynamic counterpart of that game. To concentrate on the strategic aspects within the dynamic model we push the tactical decision (i.e., selecting the optimal quantity) to the background and deal with the so-called reduced-form profit function, making the firms' flows of profits a function of unit costs. Unit costs of the firms serve as so-called "state variables" that are governed through the "control" variable, namely R\&D expenditures. Another important feature here is that passage from a two-stage model to a dynamic one requires the introduction of a specific adjustment parameter that captures the speed with which the R\&D investments translate into the unit cost reduction (see, for example, Fersthman and Kamien, 1987; and Stenbacka and Tombak, 1993 for utilization of a similar approach). This makes our model more realistic because now it mimics the unavoidable time delay between $R \& D$ investment and corresponding R\&D output. The dynamic approach also enables us to study the behavior of the strategic variable over time and some of its comparative dynamic effects, as well as the adjustment process, all of which are missing in the simple two-stage framework. Finally and most importantly, in an explicit dynamic model we can analyze how the optimal strategy of a firm that possesses a strategic advantage may lead to a change in market structure over time and thus create persistence of monopoly. This phenomenon is not possible in a static two-stage game. In other words, the strategic advantage of Firm 1 would enable it to exhibit pre-emptive behavior (or strategic predation) on its rival, turning the initial duopoly market structure into a monopoly.

Our analysis provides the following new insights:

a) Strategic predation becomes an even more attractive strategy to pursue when the adoption of new technology accelerates. More specifically, the parameter space in which strategic predation is optimal increases with the speed of the adjustment parameter and soon becomes a dominant part of this region. The intuition is that during the predation period (up to certain time $T$ ), the firm might be willing even to incur losses in order to enjoy monopoly profit from time $T$ onward. Thus, unlike a static game, in a fully dynamic model the costs of predation last only for a limited period and have to be contrasted to the infinite stream of monopoly profit afterwards. As a consequence, Firm 1 displays more aggressive behavior compared to its behavior in the two-stage game. Moreover, the innovative effort and output are usually bigger (and the price is lower) compared to the situation in which the leading firm adopts an accommodation strategy. This in turn results in larger generated social welfare in a monopoly than in a related duopoly setup. However, for a comparison of these two strategies (accommodation versus strategic predation) to be possible, 
both strategies have to be initially feasible, and that in turn requires the level of R\&D spillovers not to be "too large". Thus, our model generates results that are consistent with recent empirical findings reported in the "Economic Focus" (The Economist, May 2004). ${ }^{4}$

b) The underling dynamic optimization problem in the case of strategic predation is rather different than in the case of duopoly, where firms maximize their discounted profit over an infinite time horizon. In the case of strategic predation, Firm 1 aims to minimize the time that leads to the expulsion of Firm 2 from the market. The idea here is that Firm 1 may even bear temporary losses in order to enjoy the monopoly position later on. Imposing an upper bound on the sustainable strategic losses that Firm 1 is willing to sacrifice over the period from zero till $T$ suffices to determine the lower bound on the minimum time to force the exit. This approach formalizes the "long-purse" story.

c) The time pattern of $R \& D$ investment crucially depends on the equilibrium strategy: If accommodation is the optimal strategy, then Firm 1 commits to the R\&D path which steadily increases over time towards the unique steadystate value. When, on the other hand, strategic predation is the optimal strategy, the time profile of $R \& D$ is reversed: that is, the shorter the target time, $T$, at which Firm 2 is forced to exit, the higher the "predatory" level of R\&D investment has to be. In other words, the level of optimal R\&D investment decreases with the increase in the target time. (Note that to force an immediate exit of Firm 2 is not viable since it would require an infinite amount of R\&D, when the speed of adjustment is finite.)

d) As a finding of independent interest, we show that the steady-state values of R\&D investment in a dynamic model can be interpreted as generalized values of the equilibrium values obtained in the two-stage approach. If the adjustment is instantaneous (meaning that there is no time delay between R\&D input and its output) as implicitly assumed in a two-stage game, or if the rate of time preference (or interest rate) is neglected, then these two sets of values coincide.

\section{The Two-Stage Competition}

The basic static model is a two-stage game (see, for instance, Žigič 1998, 2000). In the first stage, Firm 1 chooses its R\&D expenditure $x$ that, at the same time,

\footnotetext{
${ }^{4}$ Etro (2004) developed an alternative model that is also consistent with the above stylized facts. In his model, the persistence of monopoly requires a large number of potential entrants.
} 
represents the level of $R \& D$ investment. In the second stage, the firms compete in quantities. Firm 1 has unit costs of production $c_{1}$ such that:

$$
c_{1}=c_{0}-\sqrt{g x}, \quad x \leq \frac{c_{0}^{2}}{g}
$$

where the parameters $g$ and $c_{0}$ describe the efficiency of the $R \& D$ process and preinnovative unit costs, respectively. The expression $\sqrt{g x}$ is an "R\&D production function," where, as in Chin and Grossman (1990), $g \in(0,4)$ (the upper bound of this interval is determined by the required positivity of the monopoly output).

Firm 2 benefits through spillovers from the R\&D activity carried out by Firm 1. Its unit cost function is

$$
c_{2}=c_{0}-\beta \sqrt{g x}, \quad \beta \in[0,1],
$$

where $\beta$ denotes the level of spillovers (which, say, reflects the strength of intellectual property rights $[\mathrm{IPR}]$ protection).

We assume the linear inverse demand function: $p=A-Q$. Parameter $A$ captures the size of the market (where $A>c_{0}$ ), variables $q_{1}$ and $q_{2}$ denote the quantities of the two firms' productions, and $Q \equiv q_{1}+q_{2}$ represents the aggregate supply.

In the second stage, given Firm 1's R\&D investment, the two firms engage in Cournot-Nash competition. Firm 1 maximizes profit net of the R\&D expenditures. The first-order conditions of firms' profit maximization yield

$$
c_{1}=A-2 q_{1}-q_{2}, \quad c_{2}=A-q_{1}-2 q_{2} .
$$

Solving the "reaction functions" yields the Cournot equilibrium outputs and price as functions of $R \& D$ investment:

$$
q_{1}=\frac{A-2 c_{1}+c_{2}}{3}, \quad q_{2}=\frac{A+c_{1}-2 c_{2}}{3}, \quad p=\frac{A+c_{1}+c_{2}}{3} .
$$

Substituting expressions (4) into the profit function yields Firm 1's profit function expressed in terms of $\mathrm{R} \& \mathrm{D}$ investment:

$$
\pi_{1}(x)=\frac{\left(A-2 c_{1}+c_{2}\right)^{2}}{9}-x=q_{1}^{2}-x
$$

In the first stage of the game, Firm 1 selects $x$ to maximize its profit. By substituting expressions (1) and (2) for $c_{1}$ and $c_{2}$ into (5) and maximizing with respect to R\&D 
investment,${ }^{5}$ we obtain:

$$
x^{*}=\frac{\left(A-c_{0}\right)^{2}(2-\beta)^{2} g}{\left(9-(2-\beta)^{2} g\right)^{2}} .
$$

It is straightforward to check that Firm 1's R\&D effort decreases with an increase in spillovers, that is, $\frac{\partial x^{*}}{\partial \beta}<0$.

Since spillovers are in general imperfect $(\beta<1)$, there is a critical value of $R \& D$ efficiency $\tilde{g}_{d}$ (leading to critical unit cost asymmetry between two firms, which in turn leads to zero profit of Firm 2), defined as a function of $\beta$ by

$$
\tilde{g}_{d}(\beta)=\frac{3}{(1-\beta)(2-\beta)},
$$

such that for $g>\tilde{g}_{d}$ duopoly ceases to exist (see Figure 1$)^{6}$. Equivalently, for any given $g$, there exists a critical value $\tilde{\beta}_{d}$ below which duopoly is not viable. This critical value is simply obtained by inverting (7).

When R\&D efficiency exceeds $\tilde{g}_{d}$ two possibilities may occur: unconstrained monopoly and monopoly constrained by the credible threat of entry by Firm 2 (or shortened "constrained monopoly"). To see this, let us look first at the optimal quantity, R\&D expenditures, and price if unconstrained monopoly emerges. Firm 1 , which is now assumed to be a monopolist, maximizes

$$
\max \pi_{m}=\left(A-q_{m}\right) q_{m}-c_{1} q_{m}-x .
$$

The first-order condition for a maximum yields $A-2 q_{m}-c_{1}=0$. Solving for $q_{m}$ and substituting in (8) yields $\pi_{m}(x)$. Substituting expression (1) for $c_{1}$ into the $\pi_{m}(x)$ and maximizing with respect to the $\mathrm{R} \& \mathrm{D}$ investment $(x)$, we obtain

$$
\tilde{x}_{m}=\frac{\left(A-c_{0}\right)^{2} g}{(4-g)^{2}}
$$

with the corresponding price

$$
\tilde{p}_{m}=\frac{A(2-g)+2 c_{0}}{4-g}
$$

(note that spillovers play no role in the case of monopoly).

\footnotetext{
${ }^{5}$ We assume that $c_{0}$ is sufficiently large in all cases to ensure that the non-negativity constraint on $c_{1}$ does not bind. The second-order condition is satisfied for all permissible values of parameters, so the optimal expenditure $x^{*}$ is always positive.

${ }^{6}$ We use $\sim$ (tilde) sign to mark static values, while in the dynamic model tilde is omitted in congruent variables.
} 
To find the parameter values which allow for pure monopoly to exist, we have to evaluate the reduced profit function of Firm 2, that is, $\pi_{2}^{*}(x)$, at Firm 1's optimal $\mathrm{R} \& \mathrm{D}$ investment level expressed in terms of parameters, and determine the region of parameters that leads to $\pi_{2}^{*}\left(\tilde{x}_{m}\right) \leq 0$. Equivalently, for Firm 1 to acquire an unconstrained monopoly position, it is necessary that $\tilde{p}_{m} \leq c_{0}-\beta \sqrt{g \tilde{x}_{m}}$. Such a post-innovative situation is that in which "drastic innovation" takes place (see Tirole, 1990). By substituting for $\tilde{p}_{m}$ and $\tilde{x}_{m}$ in the above expression we obtain the critical efficiency $\tilde{g}_{p}$ as a function of $\beta$ :

$$
\tilde{g}_{p}(\beta)=\frac{2}{1-\beta}
$$

such that for $g>\tilde{g}_{p}$ the equilibrium market form is unconstrained monopoly. The critical spillover level below which Firm 1 gains an unconstrained monopoly position is labeled as $\tilde{\beta}_{p}$.

However, if we compare this critical condition with the one required to sustain an asymmetric duopoly, we see that there is a region of parameters $\beta$ and $g$ where there is neither pure monopoly nor sustainable duopoly (the area between $\tilde{g}_{p}$ and $\tilde{g}_{d}$ in Figure 1).

\section{Insert Figure 1 HERE}

If the degree of spillovers and the efficiency of cost reductions happen to be in this region, Firm 1 exhibits so-called "strategic predation," (i.e., it chooses R\&D expenditures in such a way as to cause $q_{2}^{*}=0$ in equilibrium and thus induces the exit of Firm 2). Note that efficiency parameter $g$ in this situation is in the range of

$$
\frac{3}{(1-\beta)(2-\beta)} \leq g \leq \frac{2}{1-\beta}
$$

whereas $\beta$ stays below $\frac{1}{2}$. There are two useful corollaries resulting from the above discussion: Firm 1 can enjoy the monopoly position only if spillovers are "small" $\left(\beta<\frac{1}{2}\right)$ and the $\mathrm{R} \& \mathrm{D}$ efficiency is rather high; more specifically, $g \geq \tilde{g}_{p}(\beta)$ has to hold. Second, since strategic predation is an option always available to Firm 1, this strategy is optimal only if spillovers and R\&D efficiency are in the region described by (12). Note that the region is rather small. Furthermore, the optimal R\&D level is given by

$$
\tilde{x}_{p}^{*}=\frac{\left(A-c_{0}\right)^{2}}{(1-2 \beta)^{2} g}
$$


where subscript $p$ stands for predation. Notably, in the region of optimality of predation $\tilde{x}_{p}^{*}$ increases in $\beta$.

\section{Dynamic Counterpart of the Static Model: The Case of Duopoly}

\subsection{Setting of the Problem}

We first consider the setup in which both firms operate over an infinite time horizon. Firm 1 aims to determine its optimal R\&D path that maximizes its discounted stream of profit (or, equivalently, its market value) over time. In doing so it takes into account the effect of R\&D spillovers on its competitor's unit costs. As already mentioned in the introduction, it is more practical to analyze this issue by relying on the reduced form profit function, which depends only on the firms' respective unit costs. The unit costs are in turn the function of the central strategic variable, $R \& D$ investment, or expenditures ${ }^{7}$. In order to build a genuine dynamic model, we assume that it takes time for $R \& D$ investment to transform into a decrease in unit costs (otherwise the problem would be inherently static; see discussion in footnote 15). Thus, there is a "speed of adjustment" coefficient that captures the above-mentioned time delay (more precisely, the inverse of it). In this respect our model closely follows that of Stenbacka and Tombak (1993) (see also Fershtman and Kamien, 1987 for a similar approach).

Technically, the problem for Firm 1 is represented as an infinite horizon optimal control problem with two state and one control variable. More specifically, the problem is given by

$$
\begin{array}{r}
\max _{x(t)} I(x(t))=\int_{0}^{+\infty}\left[\Pi_{1}\left(c_{1}(t), c_{2}(t)\right)-x(t)\right] e^{-r t} d t, \\
\text { subject to } \\
\text { (a) } \frac{d c_{1}}{d t}=\mu\left(c_{0}-c_{1}(t)-\sqrt{g x(t)}\right), \\
\text { (b) } \frac{d c_{2}}{d t}=\mu\left(c_{0}-c_{2}(t)-\beta \sqrt{g x(t)}\right),
\end{array}
$$

with initial conditions $c_{1}(0)=c_{2}(0)=c_{0}$, where $x(t)$ is the control variable $(\mathrm{R} \& \mathrm{D}$ expenditures), $c_{1}(t)$ and $c_{2}(t)$ are the state variables (costs of production)..$^{8,9}$

\footnotetext{
${ }^{7}$ In the text, we use interchangeably ' $R \& D$ expenditures' and ' $R \& D$ investment'.

${ }^{8}$ Subscript 2 refers to Firm 2; subscript 1 refers to Firm 1 and will be omitted in what follows.

${ }^{9}$ Our model can be easily adapted to capture the effect of R\&D subsidization by introducing a new term $s x$ in the objective function, where $s \in[0,1]$ is the subsidization rate: $\max _{x(t)} I(x(t))=$
} 
Note that the laws of motions $(a)$ and $(b)$ require sufficient perpetual investments in order to prevent the costs from increasing. If the investment is not sufficient, the costs tend to revert back to their initial value $c_{0}$. In particular, when there is no investment in $\mathrm{R} \& \mathrm{D}$, the costs will converge to $c_{0}$. This can be interpreted as some kind of depreciation of knowledge or skills. ${ }^{10}$

At each point in time, the gross profit function (that is, $R \& D$ costs are not subtracted) is given by

$$
\Pi_{1}\left(c_{1}, c_{2}\right)=\left(p-c_{1}\right) q_{1}=\left(A-\left(q_{1}+q_{2}\right)-c_{1}\right) q_{1},
$$

with $q_{1}(t)$ and $q_{2}(t)$ denoting quantities of good produced, while constants $c_{0}$ (preinnovative unit costs) and $\beta \in[0,1]$ (the level of spillovers) are equivalent to those in the static model. New parameter $\mu>0$ represents the speed of adjustment, while $g$, the efficiency of $R \& D$ process, now belongs to the interval $(0,4 \rho)$ with some $\rho \geq 1$, due to the requirement for monopoly output to be positive in the dynamic context (see Section 4.4 or Vinogradov and Žigič, 1999). Parameter $\rho$ can be viewed as a so-called "generalized discount factor" and is defined in the following subsections. Symmetrically to $\Pi_{1}$, instantaneous gross profit function for Firm $2, \Pi_{2}$ is defined as

$$
\Pi_{2}\left(c_{1}, c_{2}\right)=\left(p-c_{2}\right) q_{2}=\left(A-\left(q_{1}+q_{2}\right)-c_{2}\right) q_{2} .
$$

If $\Pi_{i}$ are maximized at each point in time, we can obtain $q_{1}$ and $q_{2}$ as functions of $c_{1}$ and $c_{2}$ from the first-order conditions (which are the same as in the two-stage model) ${ }^{11}$ and yield the quantities and price as given by (4). Then Firm 1's profit becomes

$$
\Pi_{1}=\frac{1}{9}\left(A-2 c_{1}+c_{2}\right)^{2}=q_{1}^{2}
$$

Thus the linear transformation as given by (4) brings the optimal $\Pi_{1}$ into symmetric diagonal quadratic form in the $\left(q_{1}-q_{2}\right)$ plane.

Now we are in a position to re-formulate the initial problem. Applying transfor-

\footnotetext{
$\overline{\int_{0}^{+\infty}\left[\Pi_{1}\left(c_{1}(t), c_{2}(t)\right)-x(t)+s x(t)\right] e^{-r t} d t}$. Qualitatively, little will change in our analytical approach (developed further in Sections 3 and 4) though.

${ }^{10}$ The expression $\mu\left(c_{0}-c_{i}(t)\right)$ then corresponds to the depreciation rate (with $i=1,2$ ).

${ }^{11}$ Here we implicitly assume that Firm 1 and Firm 2 form a duopoly irrespective of the value of $x$. However, later in Lemma 1 it will be shown that the duopoly is not necessarily sustainable.
} 
mation (4), state equations (14a) and (14b) read as follows:

$$
\begin{aligned}
& \dot{q}_{1}=\mu\left(B-q_{1}+\gamma_{1} \sqrt{x}\right), \\
& \dot{q}_{2}=\mu\left(B-q_{2}+\gamma_{2} \sqrt{x}\right),
\end{aligned}
$$

where $B=\frac{1}{3}\left(A-c_{0}\right), \quad \gamma_{1}=\frac{1}{3}(2-\beta) \sqrt{g}, \quad \gamma_{2}=\frac{1}{3}(2 \beta-1) \sqrt{g}$. Similarly, the price pattern can be described by the following differential equation

$$
\dot{p}=\mu\left(\left(B+c_{0}\right)+p(t)-\left(\gamma_{1}+\gamma_{2}\right) \sqrt{g x}\right) .
$$

With state equations (17)-(18), the optimal control problem (14) loses one state dimension and takes the form

$$
\begin{array}{r}
\max _{x(t)} I(x(t))=\int_{0}^{+\infty}\left(q_{1}^{2}-x(t)\right) e^{-r t} d t, \\
\text { subject to } \\
\frac{d q_{1}}{d t}=\mu\left(B-q_{1}(t)+\gamma_{1} \sqrt{x(t)}\right) .
\end{array}
$$

\subsection{Optimal Solution}

\subsubsection{The First-Order Conditions}

The first-order conditions from the Hamiltonian function associated with the above problem yield the following differential equation (see Appendix for details): ${ }^{12}$

$$
\dot{x}=2(r+\mu) x-2 \gamma \mu q \sqrt{x} .
$$

Equation (22) determines the dynamics of the optimal R\&D path. Let us introduce the new control variable $z \equiv \sqrt{x}$. Since $\dot{x}=2 z \dot{z}$, the substitution $x=z^{2}$ linearizes the equation of motion of the control variable $x(22)$; thus $\dot{z}=(r+\mu) z-\gamma \mu q$. Finally, the joint dynamics of the state and control variable is given by the following system of linear differential equations

$$
\begin{aligned}
& \dot{z}=(r+\mu) z-\gamma \mu q, \\
& \dot{q}=\mu(B+\gamma z-q),
\end{aligned}
$$

which is investigated in detail in the remaining part of this section.

\footnotetext{
${ }^{12}$ For simplicity we drop the subscript 1 in further text.
} 


\subsubsection{Existence of the Equilibrium (Steady-state) in Duopoly}

Let us define $\rho$ as $\rho=\frac{r}{\mu}+1$. Parameter $\rho$ can be interpreted as a generalized discount factor, that is, as the interest rate corrected by the speed-of-adjustment coefficient: given $r$, the higher the level of $\mu$ is, the faster $\mathrm{R} \& \mathrm{D}$ investment materializes, and the more important the future becomes.

System (23), (24) has a unique equilibrium (steady-state):

$$
\begin{aligned}
& z^{*}=\frac{B \gamma \mu}{r+\mu\left(1-\gamma^{2}\right)}=\frac{B \gamma}{\rho-\gamma^{2}}=\frac{\left(A-c_{0}\right)(2-\beta) \sqrt{g}}{9 \rho-g(2-\beta)^{2}}, \quad x^{*}=\left(z^{*}\right)^{2}, \\
& q^{*}=\frac{B(r+\mu)}{r+\mu\left(1-\gamma^{2}\right)}=\frac{B \rho}{\rho-\gamma^{2}}=\frac{3\left(A-c_{0}\right) \rho}{9 \rho-g(2-\beta)^{2}} .
\end{aligned}
$$

Since $z(t)$ must be non-negative, the equilibrium may arise only in the positive quadrant (i.e., $z^{*}>0, q^{*}>0$ ). Therefore, the equilibrium exists if and only if $\gamma^{2}<\rho$, or, equivalently, if and only if $r+\mu\left(1-\gamma^{2}\right)>0$, or $(2-\beta)^{2}<\frac{9 \rho}{g}$, or $g<\frac{9 \rho}{(2-\beta)^{2}}$.

It is straightforward to show that values (25) and (26) coincide with the static equilibrium values in the corresponding two-stage game ${ }^{13}$ if $\rho=1$, which in turn requires that either discount rate is zero or that the impact of $R \& D$ investment is instantaneous (that is, the speed of adjustment is infinite, $\mu=\infty$ ). This is a more general result than the one obtained by Kobayashi (2001), where in his somewhat different approach the steady-state values collapse to the corresponding two-stage game equilibrium only if the discount rate is zero. ${ }^{14}$ Moreover, the steady-state value of investment monotonically increases with $\mu$, since

$$
\frac{\partial z^{*}}{\partial \mu}=\frac{B \gamma r}{\left(r+\mu\left(1-\gamma^{2}\right)\right)^{2}}>0
$$

Note that similar to the two-stage game, the equilibrium values of R\&D expenditures and the quantity of good produced by Firm 1 both are decreasing functions of spillovers $\beta$ :

$$
\frac{\partial z^{*}}{\partial \beta}=\frac{\partial}{\partial \beta}\left(\frac{\left(A-c_{0}\right)(2-\beta) \sqrt{g}}{9 \rho-g(2-\beta)^{2}}\right)=\left(-\frac{\left(A-c_{0}\right) \sqrt{g}\left(9 \rho+g(2-\beta)^{2}\right)}{\left(9 \rho-g(2-\beta)^{2}\right)^{2}}\right)<0,
$$

\footnotetext{
${ }^{13}$ E.g., see equation (6) for equilibrium R\&D in a static version of our model.

${ }^{14}$ Kobayashi (2001) made a differential game version of the D'Aspremont and Jacquemin (1988) two-stage game, where the dynamics of the model stems from a depreciation of R\&D stock rather than from the speed of adjustment.
} 
thus $\partial x^{*} / \partial \beta=2 z^{*} \cdot \partial z^{*} / \partial \beta<0$. Moreover,

$$
\frac{\partial q^{*}}{\partial \beta}=\frac{\partial}{\partial \beta}\left(\frac{3\left(A-c_{0}\right) \rho}{9 \rho-g(2-\beta)^{2}}\right)=\left(-\frac{3\left(A-c_{0}\right) \rho \cdot 2 g(2-\beta)}{\left(9 \rho-g(2-\beta)^{2}\right)^{2}}\right)<0 .
$$

\subsubsection{The Dynamics of R\&D and Output}

The existence of a unique equilibrium also implies the existence of an optimal path of $R \& D$ and output converging to this equilibrium (in particular, the existence of the "optimal control" path for $x$ ), as we show below.

Lemma 1. If $\gamma^{2}<\rho$ (i.e., $g<\frac{9 \rho}{(2-\beta)^{2}}$ ) then there exists a unique optimal path of $x$, converging to the steady-state.

Lemma 2. For any $\gamma$, the optimal control always exists if either (i) $g<\frac{9}{4} \rho$, or (ii) $\mu<\frac{9}{7} r$.

For proofs of Lemmas 1 and 2 see the Appendix.

Let us now assume that in what follows the inequality $\gamma^{2}<\rho$ always holds true. Next we determine the analytical solution to system (23)-(24). Straightforward computations imply the following closed-form solution for output and R\&D (see the Appendix for technical details):

$$
\begin{aligned}
& q_{\text {opt }}(t)=-\frac{B \gamma^{2}}{\rho-\gamma^{2}} e^{\frac{1}{2}\left(\rho-1-\sqrt{(\rho+1)^{2}-4 \gamma^{2}}\right) \mu t}+q^{*} \\
& z_{\text {opt }}(t)=-\frac{B \gamma^{2}}{\rho-\gamma^{2}} \cdot \frac{2 \gamma}{\rho+1+\sqrt{(\rho+1)^{2}-4 \gamma^{2}}} e^{\frac{1}{2}\left(\rho-1-\sqrt{(\rho+1)^{2}-4 \gamma^{2}}\right) \mu t}+z^{*} .
\end{aligned}
$$

Then, the price pattern induced by investments $z_{\text {opt }}$ is

$$
p_{\text {opt }}(t)=\frac{B \gamma\left(\gamma+\gamma_{2}\right)}{\rho-\gamma^{2}} e^{\frac{\rho-1-\sqrt{(\rho+1)^{2}-4 \gamma^{2}}}{2} \mu t}+p^{*}
$$

where

$$
p^{*}=\left(B+c_{0}\right)-\left(\gamma+\gamma_{2}\right) \sqrt{g} z^{*}=A-\left(A-c_{0}\right) \frac{6 \rho-g(2-\beta)(1-\beta)}{9 \rho-g(2-\beta)^{2}}
$$

is the steady-state price. Note that if adjustment takes place instantaneously $(\mu=$ $\infty)$, then

$$
q(t) \equiv q^{*}, \quad z(t) \equiv z^{*},
$$


as predicted by the static model. ${ }^{15}$ In this case, Firm 1's maximal profit is

$$
\int_{0}^{\infty}\left[\left(q^{*}\right)^{2}-\left(z^{*}\right)^{2}\right] e^{-r t} d t=\frac{\left(q^{*}\right)^{2}-\left(z^{*}\right)^{2}}{r}=\frac{\left(A-c_{0}\right)^{2}}{\left(9-g(2-\beta)^{2}\right) r} .
$$

Also note that the optimal R\&D investment monotonically increases and the price monotonically decreases over time towards their steady-state values. ${ }^{16}$ As noted earlier, the steady-state value of investments is higher with higher values of $\mu$ and coincides with its static counterpart when $\mu \rightarrow \infty$. In this case, the adjustment becomes instantaneous, and the speed of convergence (as measured by the absolute value of the exponent in (27), (28)) monotonically increases. ${ }^{17}$ The rationale is that a higher rate of transformation of $\mathrm{R} \& \mathrm{D}$ inputs into lower unit costs (higher $\mu$ ) decreases the time gap between the $R \& D$ investment and its benefits expressed in terms of future profits. As a consequence, for higher $\mu$, the convergence of R\&D investments towards the steady-state is faster. For illustration, Figure 2 displays time paths of R\&D levels, while Figure 3 plots the growth rates of R\&D expenditures (the speed of convergence of $R \& D$ to the steady-state values), for different $\mu$.

Insert Figure 2 HERE

Insert Figure 3 HERE

\subsection{Feasibility of Duopoly}

Let us now address the issue of feasibility of a duopoly. In a duopoly scenario, quantities of goods produced by both firms must be strictly positive: $q(t)>0, q_{2}(t)>0$ for all $t \geq 0$. (Recall the initial conditions: $q(0)=q_{2}(0)=\frac{1}{3}\left(A-c_{0}\right)=B$.)

It can be easily shown (see lemma below) that Firm 1 always produces a positive quantity of goods. For Firm 2 to operate, however, it is sufficient (but not necessary) that $\beta>\frac{1}{2}$. In other words, neither strategic predation nor unconstrained monopoly are viable in this $\beta$-region: given the upper bound of technological efficiency $(g<$ $4 \rho$ ), high technological spillovers prevent the critical gap in unit costs for monopoly to occur.

Lemma 3. $q(t)>0$ for all $t \geq 0$ and all feasible $\beta, g$.

\footnotetext{
${ }^{15}$ Alternatively, we can find the optimal solution under the instantaneous adjustment scenario by applying so-called Euler's equation: See the Appendix for details of derivation.

${ }^{16}$ Obviously, the exponent is negative, since $\rho>\gamma^{2}$.

${ }^{17}$ Note that due to the condition $\gamma^{2}<\rho=1+\frac{r}{\mu}$, the inequality $\gamma<1$ is necessary in order to have the set of feasible values of $\mu$ unbounded.
} 
Lemma 4. If $\beta \in\left(\frac{1}{2}, 1\right)$, then $q_{2}(t)>0$ for all $t \geq 0$ (no matter what the value of $g$ is).

For proofs of Lemmas 3 and 4 see the Appendix.

If the steady-state value of $q_{2}$ were non-positive, $q_{2}^{*} \leq 0$, it would indicate that Firm 2 cannot compete with Firm 1 in the long run. Thus the inequality $q_{2}^{*} \leq$ 0 implies that the duopoly is not sustainable in the long run and the strategic predation may become the optimal strategy. In other words, if there exists $T$ such that $q_{2}(T)=0$ then Firm 2 may not be capable of survival after time $T$ ( $T$ can be either finite or infinite). If Firm 1 eliminates Firm 2 at (finite) time $T$, we say that Firm 1 exhibits strategic predation.

Let us define

$$
g_{d}=\frac{3 \rho}{(1-\beta)(2-\beta)} .
$$

Technically speaking, the condition of non-sustainability of duopoly can be formalized as follows:

Lemma 5. For $q_{2}^{*}$ to be non-positive, it is necessary that $\beta<\frac{1}{2}$ and sufficient that $g \geq g_{d}$.

For proof of Lemma 5 see the Appendix.

From Lemma 4 and Lemma 5 we conclude that Firm 1 coexists with Firm 2 if $\beta>\frac{1}{2}$, and Firm 1 eliminates Firm 2 if $g \geq g_{d}$. Note that for $g \leq 4 \rho$ these conditions cannot hold simultaneously, since $\beta>\frac{1}{2}$ implies $g_{d}>4 \rho$ (see also Figure 6 ). The border case $\beta=\frac{1}{2}$ requires an additional comment. If $\beta=\frac{1}{2}$ then Firm 2 always produces the fixed quantity (equal to $B$ ) of the good, with no attention to R\&D activity performed by Firm 1 . If $g<g_{d}$ and $\beta \leq \frac{1}{2}$ then constrained monopoly may emerge.

The following proposition summarizes our findings:

Proposition 1. Let $\beta \geq 0$. Then in the steady-state the following statements hold:

1. The condition $\beta>\frac{1}{2}$ implies that duopoly is sustainable.

2. The condition $g \geq g_{d}$ implies that duopoly is not viable in the long run.

The equality $g=g_{d}$ represents an upper boundary on values of $g$ where duopoly is feasible. It is easy to observe that $g_{d}$ decreases in $\mu$ and becomes $\frac{3}{(1-\beta)(2-\beta)}$ as 
$\mu \rightarrow \infty$. Interestingly, this is the same critical value as in the static model (see expression (7)).

Note also that condition $g \geq g_{d}$ can be rewritten as a condition for $\beta$, in the form

$\beta \leq \frac{1}{2}\left(3-\sqrt{1+12 \frac{\rho}{g}}\right)$. Furthermore, observe that viability of duopoly implies the existence of the optimal control (but not vice versa) and that the range of parameters in which dynamic duopoly is viable is broader than in its static counterpart due to the fact, that the difference in unit cost of the two firms does not occur immediately, and due to the fact that the discount rate is in general positive.

\section{Achieving Monopoly Position}

\subsection{Phase I: Strategic Predation}

Instead of dealing with an infinite-horizon problem, let us consider a time-optimal problem with a horizontal terminal line. The objective of Firm 1 now is to reach the target of eliminating of Firm 2 in the minimum amount of time and gaining a position of constrained monopolist. The time-optimal nature of the problem is conveyed by the objective functional $\max _{x(t)} \int_{0}^{T}-1 d t$, subject to the following constraints and terminal conditions:

$$
\begin{aligned}
& \dot{q}=\mu(B-q+\gamma \sqrt{x}), \quad q(0)=B, \quad q(t) \geq 0, \\
& \dot{q}_{2}=\mu\left(B-q_{2}+\gamma_{2} \sqrt{x}\right), \quad q_{2}(0)=B, \quad q_{2}(T)=0, \quad T \text { is free, }
\end{aligned}
$$

given that the optimal control $x$ lies within the interval $\left[0, x^{u}\right]$ (the value of $x^{u}$ is to be computed later; this is the so-called "big-bang control").

Since Lemma 3 implies that $q(t)>0$ for all $t$, and $q(0)=q_{2}(0)=B$, the constraints in $(33)$ do not bind. Therefore, after substituting $z$ for $\sqrt{x}$, the timeoptimal problem reads as follows:

$$
\begin{array}{r}
\max _{z(t)} \int_{0}^{T}-1 d t \\
\text { subject to } \\
\dot{q}_{2}=\mu\left(B-q_{2}+\gamma_{2} z\right), \\
q_{2}(0)=B, \quad q_{2}(T)=0, \\
T \text { is free and } z \in\left[0, z^{u}\right] .
\end{array}
$$


Solution of the above problem (see the Appendix for details) yields

$$
T=-\frac{1}{\mu} \ln \left(\frac{B+\gamma_{2} z^{u}}{\gamma_{2} z^{u}}\right)
$$

Note that the positivity of $T$ demands that both the numerator and the denominator be negative: $B+\gamma_{2} z^{u}<0$ and $\gamma_{2} z^{u}<0$. Again, this observation is consistent with the fact that predation can only take place with $\beta<\frac{1}{2}$ and $q_{2}^{*} \leq 0$.

We can also invert (36) and express $z^{u}$ as a function of $T$ :

$$
z^{u}(T)=-\frac{B}{\left(1-e^{-\mu T}\right) \gamma_{2}}=\frac{A-c_{0}}{(1-2 \beta) \sqrt{g}\left(1-e^{-\mu T}\right)} .
$$

Once $z^{u}(T)$ is known, it also becomes possible to evaluate optimal output in strategic predation from the equation

$$
\dot{q}=\mu\left(B-q+\gamma z^{u}(T)\right)
$$

Equation (38) has a closed-form solution (recall the initial condition $q(0)=B$ ):

$$
q(t)=\gamma z^{u}(T)\left(1-e^{-\mu t}\right)+B=\frac{A-c_{0}}{3}\left(1+\frac{2-\beta}{1-2 \beta} \cdot \frac{1-e^{-\mu t}}{1-e^{-\mu T}}\right) .
$$

This also implies that the output of Firm 2 (which can be obtained after substitution of (37) into (64)) is:

$$
q_{2}(t)=\frac{A-c_{0}}{3} \cdot \frac{1-e^{-\mu(T-t)}}{1-e^{-\mu T}} .
$$

Interestingly, this pattern is independent of parameters $\beta$ and $g$. However, the optimal predation time might depend on them (see Section 5.2).

In particular, at time $t=T$, when Firm 2 is eliminated, we get

$$
q(T)=\left(A-c_{0}\right) \frac{1-\beta}{1-2 \beta}
$$

and $q_{2}(T)=0$. Note that $q(T)$ is positive if and only if $\beta<\frac{1}{2}$. Hence only $\beta<\frac{1}{2}$ allows for predation. On the other hand, if $\beta \geq \frac{1}{2}$, the only feasible market structure is duopoly (see also Proposition 1).

With $q(T)$ given by (40), the firms' costs at time $T$ are $c_{1}(T)=A-2 q(T)$ and $c_{2}(T)=A-q(T)$. Interestingly, none of these values depends on time $T$. Hence, regardless of when Firm 2 is eliminated, Firm 1 has the same starting point ${ }^{18}$ as a

\footnotetext{
${ }^{18}$ I.e., the unit costs and quantities of both firms do not depend on $T$.
} 
(constrained or unconstrained) monopolist.

Note that the optimal time profile of $R \& D$ investments is declining with $T$. The shorter the desired time for the elimination of the competitor is, the larger the R\&D investment should be. This functional relationship between $z^{u}$ and $T$ can be depicted as in Figure 4. This result deserves special emphasis, for on the one hand (37) enables us to find the optimal level of $R \& D$ expenditures needed to eliminate Firm 2 after any given point in time $T$, and on the other hand it establishes the relationship between the static model and its dynamic counterpart, proving once again that the static model is in a sense just a limiting case of the dynamic one.

\section{Insert Figure 4 HERE}

Further note that, contrary to the case of duopoly, we now have $d z^{u} / d \beta>0$ and $d z^{u} / d \mu<0$. The first inequality implies that in order to eliminate the rival in a given time $T$, Firm 1 needs to invest more in R\&D when the spillovers higher. With higher spillovers, Firm 2 adopts a larger part of Firm 1's technology and the difference between their costs is therefore smaller. As a consequence, the elimination of Firm 2 requires a higher R\&D effort. In this sense spillovers support R\&D investments. The second inequality states that the quicker the speed at which the R\&D investment materializes in the unit cost reduction, the lower are the predatory expenditures that lead to expulsion of Firm 2. Intuitively, higher speed of adjustment causes the reduction of costs to be more rapid and thus allows Firm 1 to eliminate the rival earlier. Therefore, the same targeted time of elimination requires smaller investments. ${ }^{19}$

In particular, if the speed of adjustment is unlimited $(\mu \rightarrow \infty)$, then for any $T$, $z^{u}$ converges to the optimal value of $\mathrm{R} \& \mathrm{D}$ predicted by the static model (cf. Žigič, 1998):

$$
\tilde{x}_{p}^{*}=\lim _{\mu \rightarrow \infty}\left(z^{u}\right)^{2}=\frac{\left(A-c_{0}\right)^{2}}{(1-2 \beta)^{2} g} .
$$

The above analysis can be read as a formalization of the "long-purse" story (see, for instance, Sherrer and Ross, 1990; and Tirole, 1990) in a distinctive way since the result is not based on information asymmetry nor imperfections in the financial markets (cf. Tirole, 1990; Telser, 1966; Bolton and Scharfstein, 1990; etc.).

Finally note that in order for strategic predation to be feasible (in our model), it is necessary that $c_{1}(T) \geq 0$. In other words, the costs do not become negative in

\footnotetext{
${ }^{19}$ Note that technically, $z^{u}(T)$ is a decreasing function of $\mu T$. Therefore, a percentage increase in the speed of adjustment $\mu$ yields the same level of $R \& D$ investments as an identical percentage increase in the targeted elimination time $T$.
} 
the predation phase. This condition can be equivalently formulated as

$$
\beta<\bar{\beta} \equiv 1-\frac{A}{2 c_{0}}
$$

The above restriction is also supported empirically by Griliches (1992) who, in his review of the empirical work on $R \& D$ spillovers, finds that typical values of $\beta$ range between 0.2 and 0.4 . Note that $\bar{\beta}<\frac{1}{2}$ due to condition $A>c_{0}$.

\subsection{Constrained and Unconstrained Monopoly}

Suppose that Firm 2 is eliminated at time $T>0$. At this point, Firm 2's unit costs become equal to the equilibrium price. From then, it will not be active in the market, if Firm 1 sets a price not exceeding Firm 2's unit costs. However, Firm 2 still remains a threat and may potentially (if the price exceeds its costs) re-enter the market later. Obviously, without such a threat, Firm 1 would set the (unconstrained) monopoly price

$$
p_{m}=\frac{A+c_{1}}{2}
$$

which comes from maximization of gross instantaneous profit $\Pi_{1}=\left(p-c_{1}\right)(A-p)$. Price $p_{m}$ corresponds to setting the monopoly quantity $q_{m}=\frac{1}{2}\left(A-c_{1}\right)$, which is actually a best response to the rival's quantity $q_{2}=0$. Technically, if Firm 1 wants to keep Firm 2 out of the market, it maximizes the gross instantaneous profit subject to the constraint $p \leq c_{2}$. Two possibilities arise:

1. If $p_{m}<c_{2}$, then Firm 1 is free to set the monopoly price $p_{m}$ which does not allow Firm 2 to re-enter the market. In this case we say that Firm 1 is an unconstrained monopolist.

2. If $p_{m} \geq c_{2}$, Firm 1 can set $c_{2}$ as the highest price that will keep Firm 2 out of the market. ${ }^{20}$ In this case, we say that Firm 1 is a constrained monopolist.

It is crucial to understand that although Firm 2 is not active in the market, Firm 1's behavior depends on the state at which Firm 2 could re-enter the market. Therefore, we need to specify the process followed by Firm 2's costs when it is inactive. We will assume that, after Firm 2 is eliminated, its costs $c_{2}(t)$ follow the standard equation of motion $\dot{c}_{2}=\mu\left(c_{0}-c_{2}(t)-\beta \sqrt{g x(t)}\right)$ with no spillovers available any further, that is, with $\beta=0$, i.e.,

$$
\dot{c}_{2}=\mu\left(c_{0}-c_{2}(t)\right)
$$

\footnotetext{
${ }^{20}$ The profit of Firm 1 is increasing in $p$ on the interval $\left[0, p_{m}\right]$.
} 
This reflects the fact that an inactive firm does not acquire any new technology via spillovers and its costs behave as if there were no spillovers, i.e., there is some depreciation of knowledge, skills, etc. ${ }^{21}$ As a consequence, Firm 2's costs actually increase after time $T$.

Since $c_{2}$ is now independent of Firm 1's R\&D investments, we can solve equation (43) with the initial value $c_{2}(T)=c_{2 T}=A-q(T)=A-\left(A-c_{0}\right) \frac{1-\beta}{1-2 \beta}$. The solution can be written as

$$
c_{2}(t)=K e^{-\mu t}+c_{0}, \quad \text { where } K=\frac{c_{2 T}-c_{0}}{e^{-\mu T}}=-\frac{\left(A-c_{0}\right) \beta}{(1-2 \beta) e^{-\mu T}} .
$$

Recall that $c_{2}(t)$ increases over time and converges to $c_{0}$ as $T \rightarrow \infty$. Further note that at time $T$ we have $c_{2}(T)=A-q(T)=\frac{1}{2}\left(A+c_{1}(T)\right)=p_{m}(T)$, i.e., the unconstrained and constrained monopoly prices are the same. ${ }^{22}$ At this point, if Firm 1's R\&D investments are high enough, so that the monopoly price $p_{m}$ does not exceed $c_{2}$ (or, equivalently, its costs do not exceed $2 c_{2}-A$ ), then the price $p_{m}$ is sufficient to keep Firm 2 out of the market. Firm 1 then becomes an unconstrained monopolist. On the other hand, if the R\&D investments are low, the resulting monopoly price $p_{m}$ may be higher than $c_{2}$ and is hence not sufficient to keep Firm 2 out of the market. In this case Firm 1 becomes a constrained monopolist.

\subsection{Phase II: Constrained Monopoly Optimization Problem}

As argued earlier, if Firm 1 becomes a constrained monopolist, it sets price $p_{c m}(t)=$ $c_{2}(t)$. This price corresponds to quantity $q_{c m}(t)=A-c_{2}(t)$ and yields Firm 1's instantaneous gross profit

$$
\Pi_{c m}=\left(c_{2}(t)-c_{c m}(t)\right)\left(A-c_{2}(t)\right) .
$$

\footnotetext{
${ }^{21}$ There could be other ways to determine how the unit costs of Firm 2 may change after time $T$. The first alternative would be to assume that they do not change at all, i.e., $c_{2}(t)=c_{2}(T)$ for $t \geq T$. Essentially, this condition states that the inactive firm is "frozen" and can enter the market in the same state as it exited the duopolistic competition. Another plausible specification would be to consider $c_{2}(t)$ following the same equation of motion after time $T$ as before (with unchanged spillovers), i.e., $\dot{c}_{2}(t)=\mu\left(c_{0}-c_{2}(t)-\beta \sqrt{g x(t)}\right)$. Such a setting can be interpreted as if Firm 2 still acquires new technology via spillovers at the same rate as before and "waits" for the right time to enter the market again. Nevertheless, the results of our model would not change quantitatively if we replaced the current specification of Firm 2's unit cost function after time $T$ with any of the specifications mentioned here.

${ }^{22}$ Equivalently, $q_{m}(T)=q(T)$ since the monopoly quantity $q_{m}$ is the same as the best response to the rival's quantity 0 .
} 
The corresponding optimization problem then is

$$
\begin{array}{r}
\max _{x(t)} I(x(t))=\int_{T}^{+\infty}\left[\left(c_{2}(t)-c_{c m}(t)\right)\left(A-c_{2}(t)\right)-x(t)\right] e^{-r t} d t \\
\text { subject to } \\
\frac{d c_{c m}}{d t}=\mu\left(c_{0}-c_{c m}(t)-\sqrt{g x(t)}\right), \\
\frac{d c_{2}}{d t}=\mu\left(c_{0}-c_{2}(t)\right) .
\end{array}
$$

Note that the post-predatory price, which is $c_{2}(t)$, is now increasing over time. This is consistent with the empirical observation that the leader's price increases after the predation phase has been completed.

The solution to the above optimization problem is derived in the Appendix. As a result we get

$$
z_{c m}(t)=\frac{\left(A-c_{0}\right) \mu \sqrt{g}}{2}\left(\frac{1}{r+\mu}+\frac{\beta e^{-\mu(t-T)}}{(1-2 \beta)(r+2 \mu)}\right) .
$$

Observe that $x_{c m}(t)=\left(z_{c m}(t)\right)^{2}$ is monotonically decreasing over time and converges to $x_{c m}^{*}=\left(z_{c m}^{*}\right)^{2}=\frac{\left(A-c_{0}\right)^{2} g}{4(1+r / \mu)^{2}}$ as $t \rightarrow \infty$. The latter reflects the fact that as Firm 2 's costs get closer to the initial value $c_{0}$, less investment is necessary to keep Firm 2 out of the market.

\subsection{Phase II: Unconstrained Monopoly Optimization Prob- lem}

If Firm 1 becomes an unconstrained monopolist, it sets the (unconstrained) monopoly price. This price equals $p_{m}(t)=\frac{1}{2}\left(A+c_{m}(t)\right)$ and corresponds to the quantity $q_{m}(t)=\frac{1}{2}\left(A-c_{m}(t)\right)$. Thus Firm 1's optimal instantaneous gross profit function is derived as

$$
\Pi_{m}=\left(p_{m}(t)-c_{m}(t)\right) q_{m}(t)=\left(q_{m}(t)\right)^{2} .
$$

The latter is maximized subject to the standard constraint $\frac{d c_{m}}{d t}=\mu\left(c_{0}-c_{m}(t)-\right.$ $\sqrt{g x(t)}$ ). As in the case of duopoly (Section 3.1), the optimization problem can be 
rewritten into the following form identical to (20)-(21):

$$
\begin{array}{r}
\max _{x(t)} I(x(t))=\int_{0}^{+\infty}\left(q_{m}^{2}-x(t)\right) e^{-r t} d t, \\
\text { subject to } \\
\frac{d q_{m}}{d t}=\mu\left(B_{m}-q_{m}(t)+\gamma_{m} \sqrt{x(t)}\right),
\end{array}
$$

with $B_{m}=\frac{1}{2}\left(A-c_{0}\right)$ and $\gamma_{m}=\frac{1}{2} \sqrt{g}$. However, the initial condition now becomes $q_{m}(T)=q(T)$. Using a similar procedure as in Section 3.2, we obtain a system of two differential equations analogous to (23)-(24). The equilibrium values in this system are derived as

$$
\begin{aligned}
& z_{m}^{*}=\frac{B_{m} \gamma_{m}}{\rho-\gamma_{m}^{2}}=\frac{\left(A-c_{0}\right) \sqrt{g}}{4 \rho-g}, \\
& q_{m}^{*}=\frac{B_{m} \rho}{\rho-\gamma_{m}^{2}}=\frac{2\left(A-c_{0}\right) \rho}{4 \rho-g} .
\end{aligned}
$$

These are to be positive, if and only if $g<4 \rho$. Note that the derivation of equilibrium values is independent of the initial conditions and even of the predation time $T$. Therefore, the same equilibrium values would be obtained if Firm 1 had a monopolistic position from the very beginning (see Section 3.1 and Vinogradov and Žigič, 1999).

Finally, using the above initial condition, the optimal solutions are

$$
\begin{aligned}
& q_{m}(t)=\frac{\left(A-c_{0}\right)(2 \rho-g(1-\beta))}{(1-2 \beta)(4 \rho-g)} e^{\lambda_{m} \mu(t-T)}+q_{m}^{*} \\
& z_{m}(t)=\frac{\left(A-c_{0}\right)(2 \rho-g(1-\beta))}{(1-2 \beta)(4 \rho-g)} \cdot \frac{\sqrt{g}}{\rho+1+\sqrt{(\rho+1)^{2}-g}} e^{\lambda_{m} \mu(t-T)}+z_{m}^{*}
\end{aligned}
$$

where $\lambda_{m}=\frac{1}{2}\left(\rho-1-\sqrt{(\rho+1)^{2}-g}\right)$. Note that the condition $g<4 \rho$ implies $g<(\rho+1)^{2}$ and $\lambda_{m}<0$. The resulting price can th en becomputed as $p_{m}(t)=$ $A-q_{m}(t)$. Depending on the sign of $2 \rho-g(1-\beta)$, the R\&D investment may be decreasing or increasing over time. Then, the monopoly quantity $q_{m}(t)$ is moving in the same direction, whereas the monopoly price $p_{m}(t)$ is moving in the opposite direction reflecting the fact that higher $R \& D$ investments lead to lower unit costs for Firm 1 and consequently to a lower monopoly price.

\subsection{Sustainability of Constrained and Unconstrained Monopoly}

In order for unconstrained monopoly to be sustainable, it is necessary that Firm 2 not re-enter the market after time $T$. This is the case when $p_{m}(t)<c_{2}(t)$. Note that 
the unconstrained monopoly optimization problem does not take at all into account the path of Firm 2's costs. In order to prevent Firm 2 from entering the market it is especially necessary that the above inequality is satisfied for the steady-state values, i.e., that $A-q_{m}^{*} \leq c_{0}$. The latter can be equivalently rewritten as

$$
g \geq 2 \rho
$$

Thus for $g \leq 2 \rho$, Firm 1, by following the optimal path of investments, gives Firm 2 a chance to re-enter the market at some point in time $T_{r} \geq T$.

On the other hand, constrained monopoly is sustainable when $p_{c m}(t) \leq p_{m}(t)$. Otherwise, it is profitable for Firm 1 to lower the price to the unconstrained monopoly level, which still prevents Firm 2 from entering the market. Again, it is necessary to satisfy the above inequality in the steady-state (with the steady-state values in constrained monopoly), i.e., $c_{0} \leq \frac{1}{2}\left(A+c_{0}-\sqrt{g x_{c m}^{*}}\right)$. Upon substitution of the steady-state value of $x_{c m}^{*}$ derived in Section 4.3, we arrive at an equivalent inequality $g \leq 2 \rho$, which is the reverse of (51). Proposition 2 below summarizes the necessary conditions of sustainability of constrained and unconstrained monopoly:

Proposition 2. Assume that Firm 2 is eliminated at time T. Then:

1. For unconstrained monopoly to be sustainable, it is necessary that $g \geq 2 \rho$.

2. For constrained monopoly to be sustainable, it is necessary that $g \leq 2 \rho$.

This proposition draws a line between constrained and unconstrained monopoly. It shows that constrained monopoly is not sustainable if the efficiency of $R \& D$ investments $g$ is high enough. Intuitively, high efficiency of R\&D allows Firm 1 to decrease its costs below the level $2 c_{2}(t)-A$ and switch to unconstrained monopoly price $\frac{1}{2}\left(A+c_{1}\right)$. On the other hand, unconstrained monopoly is not sustainable if $g$ is low enough. With low efficiency of R\&D, keeping Firm 2 out of the market requires high investments. Firm 1 may therefore prefer to reduce its investments and switch to a constrained monopoly regime. ${ }^{23}$

\footnotetext{
${ }^{23}$ Note that the necessity of the sustainability conditions in Proposition 2 emerges from the comparison of the steady-state values. Prior to reaching the steady-state, feasible strategy for Firm 1 after elimination of Firm 2 could be (multiple) switching between constrained and unconstrained monopoly regimes. In particular, such a strategy might be optimal when $g$ is close to $2 \rho$, i.e., the difference between steady-state values is small. In further analysis we abstract from the possibility of such switching. The latter means that in some cases our analysis might approximate a more complex dynamics. Still, we believe that the approximation is fairly precise.
} 


\section{Accommodation versus Strategic Predation}

\subsection{Choosing Optimal Strategy}

Finally we are in a position to determine what would be the best strategy for Firm 1. It can opt for one of the two basic strategies:

1. Accommodation: Optimize its duopoly profit over time.

2. Strategic predation: In the first stage minimize the time needed to eliminate Firm 2 for good (which incurs losses of profit) and then in the second round enjoy (constrained or unconstrained) monopoly position.

The comparison is straightforward: in both situations it is technically feasible to evaluate the overall profit and determine the optimal strategy. Note that for strategic predation the profit is comprised of two parts corresponding to the predation phase and constrained or unconstrained monopoly phase. However, depending on the underlying parameters some of the strategies might not be sustainable.

\subsection{Assessing Optimal Predation Timing}

Since the equilibrium and the optimal paths in duopoly are discussed in detail in Section 3, we focus here on the second strategy of Firm 1. Such a strategy initially aims to eliminate the competitor (recall that we assume duopoly to be an initial market structure); once the rival firm is crowded out from the market, Firm 1 enjoys the position of constrained or unconstrained monopolist afterwards.

We start by evaluating the profit (loss) $I_{p}(T)$ associated with the first phase of the competition:

$$
I_{p}(T)=\int_{0}^{T}\left[(q(t))^{2}-\left(z^{u}(T)\right)^{2}\right] e^{-r t} d t
$$

When Firm 1 attempts to gain the position of monopolist by given time $T$, it sets $\mathrm{R} \& \mathrm{D}$ expenditures at the (constant) level dictated by (37), and with $q(t)$ defined by (38). Substituting the closed-form solution (39) together with (37) into the profit 
function (52), we arrive at the explicit expression for $I_{p}(T)$ :

$$
\begin{aligned}
I_{p}(T)= & \int_{0}^{T}\left[\left(\gamma z^{u}(T)\left(1-e^{-\mu t}\right)+B\right)^{2}-\left(z^{u}(T)\right)^{2}\right] e^{-r t} d t \\
= & \left(\gamma z^{u}(T)\right)^{2} \frac{1-e^{-(2 \mu+r) T}}{2 \mu+r}- \\
& -2 \gamma z^{u}(T)\left(\gamma z^{u}(T)+B\right) \frac{1-e^{-(\mu+r) T}}{\mu+r}+ \\
& +\left(\left(\gamma z^{u}(T)+B\right)^{2}-\left(z^{u}(T)\right)^{2}\right) \frac{1-e^{-r T}}{r} .
\end{aligned}
$$

The resulting expression is rather complicated. Note, however, that with instantaneous adjustment $(\mu \rightarrow \infty)$, the optimal predation profit becomes

$$
\frac{\left(A-c_{0}\right)^{2}}{(1-2 \beta)^{2} r g}\left[(1-\beta)^{2} g-1\right]\left(1-e^{-r T}\right)
$$

In the constrained monopoly optimization problem discussed in Section 4.3, the optimal R\&D level was uniquely defined in equation (46). Thus the evolution of costs $c_{c m}(t)$ in program (45) can be explicitly derived from the equation $\dot{c}_{c m}=$ $\mu\left(c_{0}-c_{c m}(t)-\sqrt{g x_{c m}}\right)$, with $x_{c m}=z_{c m}^{2}$, as given by (46). Using the boundary condition $c_{c m}(T)=c_{1}(T)$, we can obtain a closed-form solution and, together with $c_{2}$ as given by (44), substitute it into the profit function:

$$
I_{c m}(T)=\int_{T}^{+\infty}\left[\left(c_{2}(t)-c_{c m}(t)\right)\left(A-c_{2}(t)\right)-x_{c m}(t)\right] e^{-r t} d t
$$

This equation uniquely defines the optimal constrained monopoly profit as a function of time $T$ when the position of constrained monopolist is gained. Since $c_{2}(t), z_{c m}(t)$, and since $c_{c m}(t)$ can be written as functions of $(t-T)$, the profit $I_{c m}(T)$ can be written in the form $X \cdot e^{-r T}$, with $X$ being independent ${ }^{24}$ of $T$. This is a consequence of the fact that the initial values in the second phase (i.e., at time $T$ ) do not depend on $T$. Hence, the constrained monopoly profit depends on $T$ only through the discount factor and $X$ can be interpreted as the present value of all future profits at the time Firm 2 is eliminated. ${ }^{25}$ Note that when the adjustment is instantaneous

\footnotetext{
${ }^{24}$ The expressions involved in what follows are rather cumbersome. On the other hand, they play secondary - if any - role in our analysis and thus are not presented explicitly, for the sake of readability of the model. Technicalities of computations and simulations are available from the authors upon request.

${ }^{25}$ Technically, we have $I_{c m}(T)=\int_{T}^{\infty} f(t-T) e^{-r t} d t=e^{-r T} \int_{T}^{\infty} f(t-T) e^{-r(t-T)} d t$. After substitution $s=t-T$, the integral reduces to $\int_{0}^{\infty} f(s) e^{-r s} d s$, which does not depend on $T$.
} 
$(\mu \rightarrow \infty)$, the optimal constrained monopoly profit becomes

$$
\frac{\left(A-c_{0}\right)^{2} g}{4 r} \cdot e^{-r T}
$$

Finally, in order to find the optimal $T$ (if any) that maximizes the total profit of Firm 1 pursuing a predation strategy we have to solve the following univariate unconstrained optimization problem:

$$
\max _{T}\left[I_{p}(T)+I_{c m}(T)\right]
$$

The above maximization problem represents the trade-off between incurring high costs in order to eliminate Firm 2 early, or delaying (high) constrained monopoly profits when Firm 2 is eliminated later. Recall that in the predation phase the optimal R\&D investments are decreasing in $T$. Hence early elimination (i.e., low $T$ ) requires significant $R \& D$ investments in the predation phase. This may even lead to instantaneous losses (i.e., the instantaneous profit is negative). These losses are compensated later when Firm 2 is eliminated. On the other hand, when elimination is delayed (i.e., $T$ is high), Firm 1 invests less in R\&D in the predation phase, but at the same time delays high profits earned in the constrained monopoly phase (as noted above, the present value of those profits $X$ is independent on $T$ ).

The optimal value of $T$ can be computed from the first-order condition. However, the resulting equation (with $T$ as unknown) is not solvable analytically, unless $\mu \rightarrow$ $\infty$. Till the end of this section, we mainly focus on the case of instantaneous adjustment.

Intuitively, when the speed of adjustment increases, the unit costs decrease more rapidly. As a consequence, Firm 1 will eliminate its rival earlier, i.e., the optimal predation time $T$ decreases. Figure 5 supports this intuition and shows the dependence of the optimal predation time $T$ on the speed of adjustment $\mu{ }^{26}$

\section{Insert Figure 5 HERE}

When $\mu \rightarrow \infty$, from (53) and (54) we obtain that the profit from predation strategy is decreasing in $T$ whenever $g<2$, i.e., (whenever) constrained monopoly is sustainable ${ }^{27}$ (see the Appendix for details). Hence the optimal value of $T$ is zero. This reflects the fact that the instantaneous adjustment allows Firm 1 to eliminate the rival immediately. In this case it has a profit given by (54) with $T=0$.

\footnotetext{
${ }^{26}$ These results were obtained numerically. See Footnote 29 for more details on numerical simulations.

${ }^{27}$ Note that $\rho \rightarrow 1$ as $\mu \rightarrow \infty$.
} 
We can proceed in a similar manner when Firm 1 becomes an unconstrained monopolist in the second phase. In this case the profit from the second phase is

$$
I_{m}(T)=\int_{T}^{\infty}\left[\left(q_{m}(t)\right)^{2}-\left(z_{m}(t)\right)^{2}\right] e^{-r t} d t
$$

with $q_{m}(t)$ and $z_{m}(t)$ given by (49)-(50). Again, the above equation uniquely defines the optimal unconstrained monopoly profit as a function of time $T$ when the position of unconstrained monopolist is gained. Since $q_{m}(t)$ and $z_{m}(t)$ can be written as functions of $(t-T)$, the profit $I_{m}(T)$ can again be written in the form $X \cdot e^{-r T}$, with $X$ being independent of $T$. When the adjustment is instantaneous $(\mu \rightarrow \infty)$, the optimal unconstrained monopoly profit becomes

$$
\frac{\left(A-c_{0}\right)^{2}}{(4-g) r} \cdot e^{-r T} .
$$

In order to find the optimal predation time $T$ that maximizes the total profit of Firm 1 pursuing a predation strategy with unconstrained monopoly in the second phase, we have to solve the following univariate unconstrained optimization problem:

$$
\max _{T}\left[I_{p}(T)+I_{m}(T)\right]
$$

The first-order condition for this problem is an equation with $T$ as unknown, which is not solvable analytically. The dependence of the optimal predation time $T$ on the speed of adjustment $\mu$, in the case of unconstrained monopoly is shown on Figure 5 (the upper curve). Drawing on the same intuition as in the constrained monopoly case, the figure suggests that the optimal predation time decreases with increasing $\mu$.

Again when $\mu \rightarrow \infty$, from (53) and (56) we obtain that the profit from predation strategy is decreasing in $T$ (see the Appendix for details). Hence the optimal value of $T$ is zero, which reflects the fact that when the adjustment is instantaneous, Firm

1 eliminates the rival immediately. Then its profit is $\frac{\left(A-c_{0}\right)^{2} g}{(4-g) r}$, as given by (56) with $T=0$.

\subsection{Long-Run Optimality}

In order to assess the optimal strategy for Firm 1, we now compare its two possible payoffs: accommodating strategy payoff (or duopoly payoff) defined by (14), and the payoff that arises from dynamic strategic predation, with either constrained or unconstrained monopoly in the second phase. Lemma 2 implies that both constrained and unconstrained monopoly cannot be simultaneously sustainable (with exception 
of $g=2 \rho$, which the corresponds to a set of measure zero).

As $g>g_{d}$ yields a clear-cut prediction of monopoly (Proposition 1), $\beta>\frac{1}{2}$ yields a clear-cut prediction of duopoly (see Lemmas 4-5 and Proposition 1 and Section 4.1), we will further restrict our comparison of the accommodation and predation strategies to the region

$$
\mathcal{R}=\left\{(\beta, g) \in \mathbb{R}^{2}: 0 \leq \beta<\frac{1}{2}, 0<g<g_{d}\right\}
$$

Further denote $\mathcal{R}_{c m}=\{(\beta, g) \in \mathcal{R}: g<2 \rho\}$ the region where only constrained monopoly can be sustained, and $\mathcal{R}_{m}=\{(\beta, g) \in \mathcal{R}: g>2 \rho\}$ the region where only unconstrained monopoly can be sustained. We then need to compare the profit from duopoly to the profit from strategic predation with constrained monopoly (given by problem (55)) in region $\mathcal{R}_{c m}$, and the profit from duopoly to the profit from strategic predation with unconstrained monopoly (which is given by problem (57)) in region $\mathcal{R}_{m}$. The regions are illustrated in Figure $6 .{ }^{28}$ As indicated, the curve represents the equality $g=g_{d}$, which is the upper boundary for duopoly to be feasible. As mentioned in Section 3.3, this boundary shifts downwards with increasing $\mu$. Thus as speed of adjustment increase, the region below, at which duopoly is feasible, shrinks. This is intuitive since a larger value of $\mu$ enables Firm 1 to attain cheaper and faster the critical unit cost difference that eventually may lead to monopoly. The horizontal line represents the equality $g=2 \rho$, which is the boundary between constrained and unconstrained monopoly. Again, this line shifts downwards as $\mu$ increases. Thus, unconstrained monopoly becomes easier to sustain than constrained monopoly (note that the upper boundary $g=4 \rho$ shifts downwards too). The intersection of these boundaries, namely $g=2 \rho$ and $g=g_{d}$, is given by equation $\beta^{2}-3 \beta+\frac{1}{2}=0$, which implies $\beta=\beta_{0} \equiv \frac{1}{2}(3-\sqrt{7}) \approx 0.1771$.

\section{Insert Figure 6 HERE}

As mentioned in Section 4.1, our model of predation is feasible only if $\beta<\bar{\beta}$ as given by (41). However, note that in all cases the optimal values of $q, z$, and price margins (defined as the difference of price and unit costs) are homogeneous of degree 1 in $\left(A, c_{0}\right)$. Moreover, they can be written in the form $\left(A-c_{0}\right) \cdot X$, where $X$ is independent of both $A$ and $c_{0}$. Therefore, in all cases the optimal profits, consumer surplus, social welfare, and present value of $\mathrm{R} \& \mathrm{D}$ investment are homogeneous of degree 2 in $\left(A, c_{0}\right)$ and can be written in the form $\left(A-c_{0}\right)^{2} \cdot Y$, with $Y$ being independent of both $A$ and $c_{0}$. Hence, any comparison of those variables does not

\footnotetext{
${ }^{28}$ Regions $\mathcal{R}_{c m}$ and $\mathcal{R}_{m}$ are labeled as "CM/D" and " $U M / D$ ", respectively.
} 
depend on $A$ and $c_{0}$; it can depend only on parameters $\beta, g, \mu$ and $r$. Since $\bar{\beta}$ depends on $A / c_{0}$, in order to facilitate the comparison for all values of $A$ and $c_{0}$, we disregard the feasibility condition $\beta<\bar{\beta}$ and consider $\frac{1}{2}$ as the upper bound for $\beta$ (which is also the upper bound of $\bar{\beta}$ ).

Using the simulation technique, we compare predation and accommodation in region $\mathcal{R}$ (recall that duopoly is feasible in this region). We find that when the speed of adjustment $\mu$ is small, accommodation is more profitable almost everywhere in both regions $\mathcal{R}_{c m}$ and $\mathcal{R}_{m}$, as shown in Figure 7 . However, with increasing speed of adjustment, predation (with either constrained or unconstrained monopoly in the second phase) becomes likely; see Figures $8,9 .{ }^{29}$

\section{Insert Figure 7 HERE}

Insert Figure 8 HERE

Insert Figure 9 HERE

Insert Figure 10 HERE

In Figures 8 and 9, the lower boundary represents the equality between Firm 1 's profits from accommodation strategy (duopoly) and strategic predation (with constrained monopoly in region $\mathcal{R}_{c m}$ and unconstrained monopoly in region $\mathcal{R}_{m}$ ). In the region above the boundary (i.e., when R\&D efficiency $g$ is high), Firm 1 prefers strategic predation whereas in the region below, Firm 1 prefers the accommodation strategy. With increasing $\mu$, this lower boundary shifts downwards as well, and apparently more than the upper boundary, resulting in an ever-increasing parameter space for which strategic predation is the optimal strategy. Figures 11 and 12 support this intuition. ${ }^{30}$ The figures show the dependence of the area where strategic

\footnotetext{
${ }^{29}$ The simulations were performed using the Mathematica 5.0 software. The program code can be obtained from the authors upon request. In all presented simulation results we used the values $r=0.05, A=1$, and $c_{0}=0.8$ (however, due to the discussion above, the results do not depend on values of $A$ and $c_{0}$ ). In this simulation, given the value of $\mu$, Firm 1's profits from duopoly and strategic predation (for optimal $T$ solving the problem (55) or (57)) were computed for values of $(\beta, g)$ taken from a grid with density $0.0025 \times 0.025$ on the set $\left[0, \frac{1}{2}\right) \times(0,4 \rho)$. Figures 7,8 , and 9 show the results for values $\mu=0.2, \mu=2$, and $\mu=20$ respectively.

${ }^{30}$ The simulations have again been performed using the Mathematica 5.0 software, for the same values of parameters $r, A$, and $c_{0}$ as before. For each $\mu$ from the grid with density 0.5 on $[0.5,100]$, we computed the area as integral of a piecewise linear function approximating the lower boundary (in 100 points with an absolute error lower than $10^{-4}$ ).
} 
predation is optimal in regions $\mathcal{R}_{c m}$ and $\mathcal{R}_{m}$, respectively, on the speed of adjustment $\mu$. Hence if we think of the joint distribution of $\beta$ and $g$ to be roughly uniform, we may say that predation is more likely when the speed of adjustment $\mu$ is higher.

Insert Figure 11 HERE

Insert Figure 12 HERE

Figure 10 shows the set of parameters where predation is optimal, when adjustment is instantaneous (i.e., $\mu \rightarrow \infty$ ). This can be obtained by comparing the duopoly profit (31) with either (54) or (56). As opposed to the previous cases, here it is possible to find an explicit formula for the lower boundary and compute the area where predation is optimal. We obtain that Firm 1 chooses strategic predation in the whole region $\mathcal{R}_{m}$. In region $\mathcal{R}_{c m}$, Firm 1 chooses strategic predation in about $71 \%$ of cases (again, provided the joint distribution of $\beta$ and $g$ is roughly uniform). The lower bound is described by formula $g=g_{\infty} \equiv \frac{9+\sqrt{81-16(2-\beta)^{2}}}{2(2-\beta)^{2}}$, which can be obtained by equating profits (31) with (54).

It can be easily computed that with instantaneous speed of adjustment, region $\mathcal{R}_{m}$ has area $0.2640 .{ }^{31}$ Figure 11 indicates that the area where predation is optimal converges towards this value as $\mu \rightarrow \infty$. Furthermore, the area of the whole region $\mathcal{R}_{c m}$ is $0.9524,{ }^{32}$ whereas predation is optimal in $\mathcal{R}_{c m}$ in a domain with area $0.6773 .{ }^{33}$ This convergence is again indicated in Figure 12.

\section{Welfare Analysis}

In the previous section we found that Firm 1 in most cases prefers accommodation to predation when the speed of adjustment is small, but prefers the opposite when the speed of adjustment is large. In this section we analyze the welfare effects of predation. We are interested in a comparison of R\&D investments, consumers surplus and social welfare in strategic predation and in accommodation. From the legal point of view, predatory behavior is mostly prohibited since it eliminates the competing firm. However, from an economic perspective, strategic predation may even be welfare enhancing. In particular, there may be significant gains from large

\footnotetext{
${ }^{31}$ The area of region $\mathcal{R}_{m}$ is $\int_{\beta_{0}}^{1 / 2}\left[\frac{3 \rho}{(1-\beta)(2-\beta)}-2 \rho\right] d \beta=(2-\sqrt{7}+3 \log (4-\sqrt{7})) \rho$.

${ }^{32}$ The area of region $\mathcal{R}_{c m}$ is $\int_{0}^{\beta_{0}} \frac{3 \rho}{(1-\beta)(2-\beta)} d \beta+\int_{\beta_{0}}^{1 / 2} 2 \rho d \beta=\left(-2+\sqrt{7}+3 \log \frac{4+\sqrt{7}}{6}\right) \rho$.

${ }^{33}$ This area can be computed as difference of the area of region $\mathcal{R}_{c m}$ and $\int_{0}^{1 / 2} g_{\infty} d \beta=\frac{1}{4}(3-$ $4 \sqrt{5}+\sqrt{17})-2 \arcsin \frac{2}{3}+2 \arcsin \frac{8}{9}$.
} 
$R \& D$ investments which are often disregarded by traditional competition policies. Recent developments in European competition policy design suggest that thew economic point of view may become more important in the future. In this sense our paper contributes to the current debate surrounding efficiency defence clause, which allows expulsion of rival firm(s) if it enhances consumer surplus and overall social welfare. $^{34}$ Here, the expulsion of a rival requires significant $R \& D$ investments in order to lower the costs. This consequently increases the output, decreases the price and hence increases consumer surplus. In line with this intuition we start by comparing $R \& D$ investments, although the analysis of $R \& D$ does not belong to welfare considerations per se. Then we continue with comparison a of consumer surplus and overall social welfare.

\subsection{R\&D Investment}

Compared to the accommodation strategy, strategic predation requires significantly higher R\&D investments in the first phase. This way Firm 1 rapidly decreases its own costs and, due to spillovers, also its rival's costs. As a consequence, the firms produce higher quantities which results in a lower price. However, as spillovers are imperfect, Firm 2's decrease in costs is less rapid and at time $T$ its costs become equal to the equilibrium price. The shorter the targeted predation time $T$ is, the more faster the decrease in unit costs is, and hence higher R\&D investment is necessary. After time T, Firm 2 is not able to compete with Firm 1, leaving it alone in the market. However, Firm 2 still may remain a threat and can re-enter the market later.

As shown in Section 3.2.3, when Firm 1 follows the accommodation strategy, its optimal R\&D investment continuously increases over time and converges to the value $x^{*}=\left(z^{*}\right)^{2}$, where $z^{*}$ is given by (25). On the other hand, when Firm 1 follows the strategic predation strategy, the $R \& D$ investment profile is rather different. In the predation phase, R\&D investment is constant over time and is equal to $\left(z^{u}(T)\right)^{2}$. If Firm 1 gains the position of constrained monopolist in the second phase, then the $\mathrm{R} \& \mathrm{D}$ investment profile is described by function $x_{c m}(t)$, which is decreasing over time towards its steady-state value $x_{c m}^{*}$. But if Firm 1 becomes an unconstrained monopolist in the second phase, then the R\&D investment profile is described by function $x_{m}(t)$ converging towards the steady-state value $x_{m}^{*}$, but may be either decreasing or increasing over time, depending on parameters. ${ }^{35}$

\footnotetext{
${ }^{34}$ Etro (2006b) gives a nice summary of the controversy. See also Rey et al. (2005), and the discussion paper on the reform of Art. 82 of the Treaty on exclusionary abuses by the European Commission, 2005.

${ }^{35}$ See Sections 4.3 and 4.4 for details. Following previous notation, we define $z_{c m}=\left(x_{c m}\right)^{2}$ and
} 
Comparing the investment levels in the predation phase to the levels for accommodation, we obtain

$$
\frac{z^{u}(T)}{z^{*}}=\frac{9 \rho-g(2-\beta)^{2}}{g(2-\beta)(1-2 \beta)} \cdot \frac{1}{1-e^{-\mu T}}>\frac{1}{1-e^{-\mu T}}>1
$$

everywhere in region $\mathcal{R}$. As we can see, $R \& D$ investment in the predation phase is higher than steady-state investment in duopoly. Since R\&D investment in duopoly is increasing over time, then

$$
z^{u}(T)>z_{\text {opt }}(t), \quad \text { for } t \in(0, T]
$$

confirming our intuition that strategic predation requires higher R\&D investments during the predation phase.

On the other hand, the relation between the investment in duopoly and the investment in constrained or unconstrained monopoly phase is not so clear-cut. It can be easily shown that all steady-state values $z^{*}, z_{c m}^{*}$, and $z_{m}^{*}$ are increasing in $g$, meaning that higher R\&D efficiency favors $\mathrm{R} \& \mathrm{D}$ investments in the long run. A direct computation reveals that near the upper boundary where duopoly is still feasible (i.e., when $g \rightarrow g_{d}^{-}$), the steady-state level of R\&D in duopoly is higher than the levels in constrained and unconstrained monopoly (whatever is feasible). However, this relation becomes weaker as $g$ becomes smaller, reflecting the fact that duopoly is more responsive to changes in $\mathrm{R} \& \mathrm{D}$ efficiency. In particular $z^{*}<z_{c m}^{*}$, when $g \rightarrow 0^{+}$.

As the investment level in the second phase of predation may be lower than the steady-state investment level in duopoly, there is no straightforward relation between the size of R\&D investment in the strategic predation and accommodation phases. In order to provide some insights, we compare their present values. The present value of $R \& D$ investments for the accommodation strategy is defined as $\int_{0}^{\infty} x(t) e^{-r t} d t$. The present value of $\mathrm{R} \& \mathrm{D}$ investments for the predation strategy is defined analogously, but consists of two parts: the present value in the predation phase and the present value in the constrained or unconstrained monopoly phase. As the expressions are rather complicated (we omit them here), for comparison we used numerical simulations.

We perform the simulations in the same way and for the same parameter values as we did for comparison of profits. Consistent with the above results, simulations suggest that in most cases strategic predation indeed leads to higher R\&D investment, despite the position of monopolist (constrained or unconstrained) in the sec$z_{m}=\left(x_{m}\right)^{2}$. 
ond phase. This result is rather intuitive, since in the predation phase, Firm 1 makes huge $R \& D$ investments in order to eliminate the rival. In line with Etro (2004) we therefore conclude that a leader may have greater $R \& D$ incentives than traditional economic theory suggests. According to our results, an aggressive leader engages in significant R\&D investments in order to pursue the predation strategy.

The simulations indicate that the above relation holds for all parameter values (in region $\mathcal{R}$ ) when the speed of adjustment $\mu$ is small. The situation does not change significantly when $\mu$ becomes larger, ${ }^{36,37}$ although for large enough $\mu$, there is a small region close to the upper boundary where the present value of $R \& D$ investments for the accommodation strategy may become higher than the value in predation. This region corresponds, in line with the above results, to high $\mathrm{R} \& \mathrm{D}$ efficiency $g$ which makes high R\&D investment in duopoly profitable.

Insert Figure 13 HERE

Insert Figure 14 HERE

Insert Figure 15 HERE

\subsection{Consumer Surplus}

Now we turn our attention to the effects on consumers. As already argued, since investment in $R \& D$ decreases the cost of production, it increases the quantity produced and hence lowers the market price. Therefore, intuitively we can predict that higher investment in the predation phase should benefit consumers. When Firm 1 follows the predation strategy, its $R \& D$ investment lowers the price rapidly in the first phase. If it becomes a constrained monopolist in the second phase, the price will increase and converge to $c_{0}$. On the other hand, if Firm 1 becomes an unconstrained monopolist in the second phase, the price will be monotone but may be both increasing or decreasing, depending on parameters. Figures 16 and 17 show the comparison of these time patterns to the price pattern for the accommodation strategy.

\footnotetext{
${ }^{36}$ See Figures 13,14 , and 15 corresponding to $\mu=2, \mu=20$, and $\mu \rightarrow \infty$, respectively. The shaded area represents those values of parameters where the present value of $R \& D$ investments in accommodation is higher than the one in predation. The figures indicate that this region does not increase significantly with increasing $\mu$.

${ }^{37}$ When $\mu \rightarrow \infty$, the present values of R\&D investments have rather simple forms: $\frac{\left(A-c_{0}\right)^{2}(2-\beta)^{2} g}{\left[9-(2-\beta)^{2} g\right]^{2} r}$ for accommodation strategy, $\frac{\left(A-c_{0}\right)^{2} g}{4 r}$ for predation with constrained monopoly, and $\frac{\left(A-c_{0}\right)^{2} g}{(4-g)^{2} r}$ for predation with unconstrained monopoly (recall that the optimal predation time is $T=0$ in this case). Figure 15 was obtained directly by comparing those values.
} 
Insert Figure 16 HERE

Insert Figure 17 HERE

For better exposition and in order to be able to evaluate the effects on social welfare, we compare the present value of consumer surplus. First consider instantaneous consumer surplus, which at any point in time $t$ can be evaluated as

$$
C S(t)=\int_{p(t)}^{A}(v-p(t)) d v=\frac{1}{2}(A-p(t))^{2}=\frac{1}{2}\left(q_{1}(t)+q_{2}(t)\right)^{2} .
$$

This is a classic form of consumer surplus for linear demand. Then the present value of consumer surplus for the accommodation strategy is

$$
C S^{*}=\int_{0}^{\infty} C S(t) d t=\int_{0}^{\infty}\left(q_{1}(t)+q_{2}(t)\right)^{2} e^{-r t} d t
$$

Since the consumer surplus is negatively related to the price, our intuition suggests that the consumer surplus should be higher, when Firm 1 follows the predation strategy.

$$
\text { Insert Figure } 18 \text { HERE }
$$

Insert Figure 19 HERE

\section{Insert Figure 20 HERE}

Indeed, it can be shown that strategic predation yields a lower price than does accommodation at any (positive) time in the predation phase. Moreover, if $g \leq$ $3 \rho /(2-\beta)$, then strategic predation also yields a lower price at any time in the constrained monopoly phase. ${ }^{38}$ As a consequence, if $g \leq 3 \rho /(2-\beta)$, then the consumer surplus from strategic predation is higher that the one from accommodation. Conversely, if $g>3 \rho /(2-\beta)$ then $p^{*}<c_{0}$, which means that the price in a constrained monopoly (converging to $c_{0}$ ) exceeds the duopoly price (converging to $p^{*}$ ) at some point in time. This reflects the fact that Firm 1 enjoys its high profits from constrained monopoly and relaxes its $R \& D$ investments, which leads to higher unit

\footnotetext{
${ }^{38}$ See the Appendix for proof of both statements. Note also that $3 \rho /(2-\beta)<2 \rho$ for any $\beta \geq 0$.
} 
costs and a higher price. In this case we cannot make a direct inference about consumer surplus. However, the intuition suggests that the difference between prices becomes significant and the consumer surplus in accommodation may exceed the one in predation, when $g$ is sufficiently high.

To complete the discussion, we again perform numerical simulations. The simulations conform to the above intuition. In particular, they show that for low values of $\mu$, consumer surplus from predation is always larger than the one from accommodation. However, similarly as for R\&D investments, when the speed of adjustment $\mu$ is large enough, there is, consistent with the above intuition, a small region where consumer surplus from accommodation is higher; see Figures 18 and $19 .{ }^{39}$ When $\mu \rightarrow \infty$, this region covers a substantial part of region $\mathcal{R}_{m}$, but only a small part of region $\mathcal{R}_{c m}$, as shown in Figure 20. ${ }^{40}$

\subsection{Social Welfare}

Social welfare consists of consumer surplus and firms' net profits (after subtracting the $R \& D$ costs). As the complexity of the problem does not allow (with the exception of small domains) us to make a clear comparison of social welfare for accommodation and predation strategies, nevertheless, as in previous cases, we compare social welfare using a simulation technique. We perform the simulations in the same way and for the same parameter values as we did for comparison of profits.

The most conspicuous finding that our analysis offers is that strategic predation becomes not only the privately optimal strategy to pursue but also the strategy that turns out to be, in general, socially optimal when the speed of adjustment is high. ${ }^{41}$ This observation sheds new light on those technologically leading firms that display fast absorption of technological progress (large $\mu$ ), and which in turn makes them aggressive market leaders through large investment in $R \& D$. In other words, the resulting high market shares are not necessarily associated with dominance, but may be the outcome of competition for the market through innovations (see also Etro, 2006b).

\footnotetext{
${ }^{39}$ The shaded area represents those values of parameters where consumer surplus in accommodation is higher than the one in predation.

${ }^{40}$ Again, when $\mu \rightarrow \infty$, the present values of consumer surplus have a rather simple form: $\frac{\left(A-c_{0}\right)^{2}[6-(1-\beta)(2-\beta) g]^{2}}{2\left[9-(2-\beta)^{2} g\right]^{2} r}$ for accommodation strategy, $\frac{\left(A-c_{0}\right)^{2}}{2 r}$ for predation with constrained monopoly, and $\frac{2\left(A-c_{0}\right)^{2}}{(4-g)^{2} r}$ for predation with unconstrained monopoly (again, recall that the optimal predation time is $T=0$ in this case). Figure 20 was obtained directly by comparing those values.

${ }^{41}$ As revealed by Figures 22, 22, and 23, with increasing $\mu$ the region in which accommodation is socially optimal (shaded area) shrinks. Moreover, when the speed of adjustment unlimitedly increases and turns instantaneous $(\mu \rightarrow \infty)$, strategic predation becomes socially optimal, with the exception of a small region (see Figure 24).
} 
Intuitively, as $\mu$ increases, the positive effect of $R \& D$ investment takes place earlier, which leads to increases of social welfare in both accommodation and strategic predation. Moreover, as the optimal predation time is decreasing in $\mu$ (see Figure 24), this effect is even stronger in case of the strategic predation. Therefore, social welfare in predation is more responsive to increases in $\mu$ than social welfare in accommodation. Consequently, for large values of $\mu$, predation is socially optimal even when Firm 1 chooses accommodation. Thus in such a situation strategic predation should be supported by appropriate government policy, like investment subsidies (see footnote 9 for a possible specification).

Besides that, there is also a small region where Firm 1 prefers predation, but where accommodation is more desirable outcome from social point of view. This region corresponds to high values of $\mathrm{R} \& \mathrm{D}$ efficiency, near the upper boundary for feasibility of duopoly (i.e., when $g$ is close to $g_{d}$ ). Section 6.2 suggests that for high values of $g$, the consumer surplus in predation is higher than the consumer surplus in accommodation. Therefore, it is not surprising that this relation also holds for social welfare.

Insert Figure 21 HERE

Insert Figure 22 HERE

Insert Figure 23 HERE

Insert Figure 24 HERE

\section{Conclusion}

The empirical findings and stylized facts concerning the relation between innovation, leadership, and market power have motivated our paper in that we aim to describe and analyze a particular setup in which the persistence of monopoly is likely to arise in the long run. More specifically, we study the situation in which the market leader undertakes pre-emptive R\&D investment ("strategic predation") that eventually leads to the exit of the follower firm. It is also important to stress that we allow the follower to benefit via $R \& D$ spillovers from the $R \& D$ activity of the leader. We then, within the same basic setup, contrast the outcomes of strategic predation 
with the outcomes in which the leader "accommodates" the follower in a duopoly market structure. This comparison enables us to study positive aspects of the two main strategies of the leader - accommodation and strategic predation - as well as social welfare implications of the two resulting market structures, duopoly and (constrained or unconstrained) monopoly.

In studying the above phenomenon, we first start with static analysis and subsequently develop a corresponding dynamic model. While the very comparison between the static model and its dynamic counterpart is an insightful exercise per se, we argue that, due to the inherently dynamic nature of innovation activity, a dynamic model is better suited at capturing both accommodating and pre-emptive or predatory behavior of the leader, and consequently, it fits better with observed empirical findings about the persistence of monopoly and its high intensity of innovative activity.

While monopoly appears as amarginal market structure in a static environment and is therefore often excluded from such an analysis by assumptions (e.g., by restrictions on parameters), in a dynamic setup when there is fast adoption of new technology, on the contrary, this marginal market structure becomes the prevalent one and strategic predation turns out to be the dominant market strategy in general. The quicker the time of innovation adoption, the larger the range in which predation becomes the optimal strategy. Both R\&D intensity and R\&D stock are likely to be larger in predation strategy than in accommodation strategy. Put together, these two facts yield a testable prediction in that the most aggressive innovative firms those that commercialize their investment in innovation quickly - are the ones likely to use strategic predation through investing large sums of money into innovative activity (cf. AT\&T, Microsoft, etc.).

As for the social welfare considerations, strategic predation as the prevalent market strategy may be socially preferable as well, since it might lead to both higher consumer surplus, and (even more often) to higher social welfare generated, despite the fact that only one firm (the leader) remains in the market in the long run. This all bears important competition policy implications. First, the size of market share per se might not be a sufficient condition for a legal offence and, second, abuses of dominant positions may not even be an issue in dynamic markets where competition takes place through investments in $R \& D$ rather than through static pricing and where the very presence of competitors constrains the behavior of market leaders. The challenge for the design of antitrust policy against predation is related to the ability of the antitrust authority to distinguish between a price that is low for other predatory purposes from a price that might be set very low as part of an efficiencyenhancing process that in turn results in enhanced competition leading in the end 
to the exit of competitors but also to the enhancement of both consumer surplus and social welfare. For instance, in the presence of network effects or learning effects it would be legitimate and consistent with vigorous competition that firms set very low prices when they are introducing new products, when they are targeting new customer segments or rivals, installed bases, or when they are in the first phase of the learning curve. Thus, a competition authority with limited knowledge of industryand firm-specific data faces a complex problem when attempting to identify those circumstances under which loss-inducing predatory prices cause harm to competition. For that reason the antitrust authorities have to be fully aware of the risks of misclassification when approaching a predation case. Nevertheless, our model clearly favors still controversial proposition of the efficiency defences that allows for otherwise abusive strategy for the dominant firm if it creates a net efficiency gains which benefits consumers. On the other hand, our results also suggest that accommodation, when chosen by the leader, may also be inefficient. The logic indicates that such inefficiency calls again for appropriate policy interventions. In order to increase social welfare, an appropriate policy should support the leader's predatory behavior, for example, in the form of subsidies.

However, our results concerning both private and social optimality of strategic predation are obtained under the assumption of the homogeneity of goods. As we know (at least from Dixit, 1979), product differentiation makes strategic predation more difficult and more costly for the leader. Moreover, strategic predation in this case leads to fewer product varieties in the market, and this in turn harms consumers. However, by the continuity argument, it is pretty safe to claim that our findings would also hold in the situation when the degree of product differentiation is not "large"; that is, when the goods are "close" substitutes.

Another policy concern that can arise from the above setup might be that policy makers worry of having only one firm in the market, as was recently the case with the General Electric and Honeywell banned merger. This could be an issue if there is no credible threat of entry from any other firm because the size of the entry barriers is high; but this again leads to Etro's remark (2006a) that the barriers to entry should be targeted rather than market leaders. In the technical sense, our analysis could be further extended in several directions. The speed of adjustment could be "endogenized" as a function of the R\&D intensity or R\&D stock, for instance. Furthermore, we could model the last, quantity competition stage between the leader and follower explicitly by relying on the concepts of state dependent strategies and Markov perfect equilibria. This approach could make the game even more "dynamic" with possibly additional insights. 


\section{A Appendix: Proofs and Derivations}

A.1 Derivation of equation (22). The Hamiltonian function associated with problem (20) is set up as

$$
\mathcal{H}\left(q_{1}, x, \lambda\right)=\left(q_{1}^{2}-x(t)\right) e^{-r t}+\lambda(t) \mu\left(B-q_{1}(t)+\gamma_{1} \sqrt{x(t)}\right) .
$$

The first-order conditions (from now on we drop the subscript 1 for convenience) are

$$
\begin{aligned}
& \mathcal{H}_{x}=-e^{-r t}+\frac{\lambda \mu \gamma}{2 \sqrt{x}}=0, \\
& \mathcal{H}_{q}=2 q e^{-r t}-\lambda \mu+\dot{\lambda}=0,
\end{aligned}
$$

and the transversality condition is

$$
\lim _{t \rightarrow+\infty} \lambda(t) q(t)=0
$$

Equation (59) relates $\lambda$ to $x$, so we can eliminate $\lambda$ and $\dot{\lambda}$ from the system (60), (21):

$$
\lambda=\frac{2 \sqrt{x}}{\gamma \mu} e^{-r t}, \quad \dot{\lambda}=\frac{\dot{x}}{\gamma \mu \sqrt{x}} e^{-r t}-\frac{2 r \sqrt{x}}{\gamma \mu} e^{-r t}
$$

and thus equation (60) becomes

$$
\dot{x}=2(r+\mu) x-2 \gamma \mu q \sqrt{x} .
$$

A.2 Proof of Lemma 1. Introducing the new time scale $d \tau=\mu d t$, the system (23)-(24) reads in matrix notation as

$$
\frac{d Y}{d \tau}=\Gamma Y+\Delta
$$

$$
\text { where } Y=\left(\begin{array}{l}
z \\
q
\end{array}\right), \quad \Gamma=\left(\begin{array}{cc}
\rho & -\gamma \\
\gamma & -1
\end{array}\right), \quad \Delta=\left(\begin{array}{c}
0 \\
B
\end{array}\right) \text {. }
$$

For matrix $\Gamma$ the following statements hold:

- $\operatorname{Tr}(\Gamma)=\rho-1=\frac{r}{\mu}>0$, which implies that the sum of eigenvalues $\lambda_{1}, \lambda_{2}$ is always positive. 
- $\operatorname{Det}(\Gamma)=-\rho+\gamma^{2}<0$, which means that the product of the eigenvalues is negative.

- $D=(\operatorname{Tr}(\Gamma))^{2}-4 \operatorname{Det}(\Gamma)=(\rho+1)^{2}-4 \gamma^{2}>(\rho+1)^{2}-4 \rho=(\rho-1)^{2} \geq 0$, which means that the eigenvalues are real.

Therefore, if $\gamma^{2}<\rho$ then the eigenvalues are real and of opposite sign (i.e., the equilibrium is a saddle). The latter proves the existence of a unique trajectory converging to the steady-state (a stable arm of a saddle). ${ }^{42}$

Q.E.D.

A.3 Proof of Lemma 2. (i) Inequality $\gamma^{2}<\rho$ can be re-arranged as

$$
\beta>2-\frac{3 \sqrt{\rho}}{\sqrt{g}}
$$

Since $\beta$ is always positive, (62) holds true when the right-hand side of (62) is negative, i.e., for $g<\frac{9}{4} \rho$. Moreover, by construction the generalized discount factor $\rho \geq 1$. As $\mu$ (the speed of adjustment) tends to infinity, $\rho$ monotonically declines to 1 , and $\min \rho=1$. Therefore, with $g<\frac{9}{4} \min \rho=\frac{9}{4}$ the right-hand side of (62) always remains negative for any constellation of $\beta, \mu$ and $r$.

(ii) Since $\max \gamma=\frac{4}{3}$, the condition $\mu<\frac{9}{7} r$ guarantees that $\rho=\frac{r}{\mu}+1>\frac{16}{9}=$ $\max \gamma^{2}$. Therefore, $\rho>\gamma^{2}$, for any $\gamma$.

Q.E.D.

A.4 Derivation of the analytical solution to system (23)-(24). The eigenvalues of $\Gamma$ are

$$
\lambda_{1,2}=\frac{\rho-1 \pm \sqrt{(\rho+1)^{2}-4 \gamma^{2}}}{2}=\frac{1}{2 \mu}\left(r \pm \sqrt{(r+2 \mu)^{2}-4 \gamma^{2} \mu^{2}}\right), \quad \lambda_{1}<0<\lambda_{2}
$$

and the eigenvectors corresponding to $\lambda_{1}$ and $\lambda_{2}$ are evaluated as

$$
U_{1}=\left(\begin{array}{c}
\frac{2 \gamma}{\rho+1+\sqrt{(\rho+1)^{2}-4 \gamma^{2}}} \\
1
\end{array}\right), \quad U_{2}=\left(\begin{array}{c}
\frac{2 \gamma}{\rho+1-\sqrt{(\rho+1)^{2}-4 \gamma^{2}}} \\
1
\end{array}\right)
$$

\footnotetext{
${ }^{42}$ Loosely speaking, an equilibrium $\left(z^{*}, q^{*}\right)$ is

1. unstable focus, if $D<0\left(\lambda_{1,2}\right.$ are complex $)$ and $\operatorname{Tr}(\Gamma)>0\left(\operatorname{Re}\left(\lambda_{1,2}\right)>0\right)$; holds true for $\gamma>\frac{\rho+1}{2}$

2. unstable node, if $D \geq 0\left(\lambda_{1,2}\right.$ are real $)$ and $\operatorname{Det}(\Gamma) \geq 0\left(\lambda_{1}, \lambda_{2} \geq 0\right)$; holds true for $\sqrt{\rho} \leq$ $\gamma \leq \frac{\rho+1}{2}$

3. saddle, if $D \geq 0$ and $\operatorname{Det}(\Gamma)<0\left(\lambda_{1}<0<\lambda_{2}\right)$; holds true for $\gamma^{2}<\rho$.
}

However, in our model the first two options are ruled out due to non-negativity of $z$. 
Therefore, the general solution to (61) becomes

$$
Y(\tau)=C_{1} U_{1} e^{\lambda_{1} \tau}+C_{2} U_{2} e^{\lambda_{2} \tau}+Y_{p}
$$

where $C_{1}, C_{2}$ are arbitrary constants and the particular solution $Y_{p}$ is a constant solution satisfying the equation $\Gamma Y_{p}+\Delta=0$, i.e.,

$$
Y_{p}=\left(\begin{array}{l}
z^{*} \\
q^{*}
\end{array}\right) .
$$

The transversality condition demands $C_{2}=0$ (in other words, the optimal solution must be bounded). The constant $C_{1}$ is determined from the initial condition $q(0)=$ $B$, which implies $C_{1}=-\frac{B \gamma^{2}}{\rho-\gamma^{2}}$.

Finally, we find the optimal control path as

$$
\begin{aligned}
& q_{\text {opt }}(\tau)=-\frac{B \gamma^{2}}{\rho-\gamma^{2}} e^{\lambda_{1} \tau}+q^{*} \\
& z_{\text {opt }}(\tau)=-\frac{B \gamma^{2}}{\rho-\gamma^{2}} \cdot \frac{2 \gamma}{\rho+1+\sqrt{(\rho+1)^{2}-4 \gamma^{2}}} e^{\lambda_{1} \tau}+z^{*}
\end{aligned}
$$

or, restoring the original time scale,

$$
\begin{aligned}
& q_{\text {opt }}(t)=-\frac{B \gamma^{2}}{\rho-\gamma^{2}} e^{\frac{\rho-1-\sqrt{(\rho+1)^{2}-4 \gamma^{2}}}{2} \mu t}+q^{*}, \\
& z_{\text {opt }}(t)=-\frac{B \gamma^{2}}{\rho-\gamma^{2}} \cdot \frac{2 \gamma}{\rho+1+\sqrt{(\rho+1)^{2}-4 \gamma^{2}}} e^{\frac{\rho-1-\sqrt{(\rho+1)^{2}-4 \gamma^{2}}}{2} \mu t}+z^{*} .
\end{aligned}
$$

Q.E.D.

\section{A.5 Optimal solution to (20)-(21) with $\mu \rightarrow \infty$, by applying Euler's equation.}

Under the instantaneous adjustment scenario, as $\mu \rightarrow \infty$, equation (21) becomes

$$
q(t)=B+\gamma z
$$

and the optimization problem (20) degenerates to

$$
\max _{z^{2}(t)} \int_{0}^{\infty}\left((B+\gamma z(t))^{2}-z^{2}(t)\right) e^{-r t} d t
$$

Euler's equation associated with this problem reduces simply to

$$
\frac{\partial}{\partial z}\left((B+\gamma z(t))^{2}-z^{2}(t)\right) e^{-r t}=0
$$


which has to be satisfied at each point in time. It yields

$$
z_{o p t}=\frac{B \gamma}{1-\gamma^{2}}
$$

Therefore, in the limiting case the optimal level of $R \& D$ expenditures is constant over time and coincides with the equilibrium value of $z^{*}$ in (25) evaluated at $\mu \rightarrow \infty$.

A.6 Proof of Lemma 3. We have $\dot{q}=\mu(B-q+\gamma z)$. Therefore $\dot{q}+\mu q=f(t)$ with $f(t)=\mu B+\mu \gamma z(t)>0$ for all $t \geq 0$. The solution to the latter equation is

$$
q(t)=e^{-\mu t}\left(B+\int_{0}^{t} f(\tau) e^{\mu \tau} d \tau\right)
$$

which is always positive.

Q.E.D.

A.7 Proof of Lemma 4. Since $\gamma_{2}>0$ for $\beta \in\left(\frac{1}{2}, 1\right)$, the proof repeats that of Lemma 3.

Q.E.D.

A.8 Proof of Lemma 5. Necessity follows from Lemma 4. To prove sufficiency, first note that $q_{2}^{*}=B+\gamma_{2} z^{*}$. Thus non-positivity of $q_{2}^{*}$ implies $B+\gamma_{2} z^{*} \leq 0$, which is equivalent to

$$
B \leq \frac{1}{3}(1-2 \beta) \sqrt{g} \cdot \frac{B \cdot \frac{1}{3}(2-\beta) \sqrt{g}}{\rho-\frac{1}{9}(2-\beta)^{2} g} .
$$

The latter inequality simplifies to

$$
1 \leq \frac{(1-2 \beta)(2-\beta)}{9 \frac{\rho}{g}-(2-\beta)^{2}}
$$

and can be further re-arranged as

$$
\frac{3 \rho}{g} \leq(2-\beta)(1-\beta), \quad \text { or } \quad g \geq \frac{3 \rho}{(2-\beta)(1-\beta)} \equiv g_{d}
$$

Given that $\rho \geq \gamma^{2}=\frac{1}{9}(2-\beta)^{2} g$, the latter inequality implies that

$$
\frac{1}{9}(2-\beta)^{2} g \cdot \frac{3}{g}<\frac{3 \rho}{g} \leq(2-\beta)(1-\beta) .
$$

Therefore, $\frac{1}{3}(2-\beta)^{2}<(2-\beta)(1-\beta)$, i.e., $\beta<\frac{1}{2}$ is necessary for $q_{2}^{*}$ to be non-positive. Q.E.D. 
A.9 Solution to the optimal predation problem. The Hamiltonian function associated with this problem is

$$
\mathcal{H}=-1+\lambda\left(\mu\left(B-q_{2}+\gamma_{2} z\right)\right)
$$

If $\lambda>0$ then the optimal $z^{o}=z^{u}$, and if $\lambda<0$ then $z^{o}=0$. The equation of motion is

$$
\dot{\lambda}=-\frac{\partial \mathcal{H}}{\partial q_{2}}=\mu \lambda
$$

which integrates to $\lambda(t)=\kappa e^{\mu t}, \kappa$ is an arbitrary constant. The transversality condition reads as $[\mathcal{H}]_{t=T}=0$, i.e.,

$$
-1+\lambda\left(\mu\left(B+\gamma_{2} z^{o}\right)\right)=0
$$

If $\lambda<0$ then $z^{o}=0$ and (63) has no solution. Therefore, $\lambda>0$, which yields $\kappa>0$ and $z^{o}=z^{u}$.

With $z^{o}=z^{u}$ for all $t$ we can express the equation of motion of the state variable as

$$
\dot{q}_{2}+\mu q_{2}=\mu\left(B+\gamma_{2} z^{u}\right)
$$

which has the solution

$$
q_{2}^{o}(t)=\left(q_{2}^{o}(0)-B-\gamma_{2} z^{u}\right) e^{-\mu t}+B+\gamma_{2} z^{u}=B+\gamma_{2} z^{u}\left(1-e^{-\mu t}\right) .
$$

Therefore, given $q_{2}^{o}(T)=0$ we obtain $B+\gamma_{2} z^{u}\left(1-e^{-\mu T}\right)=0$, which is equivalent to $(36)$.

Alternatively, the optimal predation problem can be also solved as follows. In order to eliminate Firm 2, Firm 1 must lower its price below the costs of production of Firm 2, i.e., the following condition must hold:

$$
A-q_{1}(t) \leq c_{2}(t)
$$

In other words, at the very moment the price of Firm 1 falls below the costs of Firm 2, Firm 1 becomes a constrained monopolist. Therefore, the corresponding optimization problem for Firm 1 is very similar to that elaborated earlier: the condition for becoming a constrained monopolist reads as $A-q_{1}(T)=c_{2}(T)$, or, in 
other words, $q_{1}(T)+c_{2}(T)=A$. With two equations of motion of $q_{1}$ and $c_{2}$ in hand

$$
\begin{aligned}
& \dot{q}_{1}=\mu\left(B-q_{1}+\gamma_{1} z\right), \\
& \dot{c}_{2}=\mu\left(c_{0}-c_{2}-\beta \sqrt{g} z\right),
\end{aligned}
$$

we can introduce the new variable (say, $\xi$ ), $\xi=q_{1}+c_{2}$, which must satisfy the boundary conditions $\xi(0)=q_{1}(0)+c_{2}(0)=B+c_{0}, \xi(T)=A$, and is subject to the following equation of motion:

$$
\dot{\xi}=\mu\left(B+c_{0}-\xi+\left(\gamma_{1}-\beta \sqrt{g}\right) z\right) .
$$

Therefore, with a few modifications, the optimization problem under consideration replicates problem (35):

$$
\begin{array}{r}
\max _{z(t)} \int_{0}^{T}-1 d t \\
\text { subject to } \\
\dot{\xi}=\mu\left(B+c_{0}-\xi+\left(\gamma_{1}-\beta \sqrt{g}\right) z\right), \\
\xi(0)=B+c_{0}, \quad \xi(T)=A,
\end{array}
$$

$T$ is free, and $z \in\left[0, z^{u}\right]$.

There is little wonder that the solution of (65) will be identical to (36) and (37).

A.10 Derivation of optimal solution in constrained monopoly. With $c_{2}(t)$ given by (44), the objective functional in (45) expands to the sum

$$
\int_{T}^{+\infty}\left[c_{c m}(t)\left(c_{2}(t)-A\right)-x(t)\right] e^{-r t} d t+\int_{T}^{\infty}\left[c_{2}(t)\left(A-c_{2}(t)\right] e^{-r t} d t\right.
$$

in which the second term integrates to a constant, say, $\mathcal{K}$, which does not depend on the control variable and thus can be discarded. For that reason optimization problem (45) reduces to

$$
\begin{array}{r}
\max _{x(t)} I(x(t))=\int_{T}^{+\infty}\left[c_{c m}(t)\left(K e^{-\mu t}+c_{0}-A\right)-x(t)\right] e^{-r t} d t \\
\text { subject to } \\
\frac{d c_{c m}}{d t}=\mu\left(c_{0}-c_{c m}(t)-\sqrt{g x(t)}\right) .
\end{array}
$$

In order to solve the above problem, we form Hamiltonian $\mathcal{H}=\left[c_{c m}(t)\left(K e^{-\mu t}+\right.\right.$ $\left.\left.c_{0}-A\right)-x(t)\right] e^{-r t}+\lambda(t) \mu\left(c_{0}-c_{c m}(t)-\sqrt{g x(t)}\right)$ with first-order conditions $\mathcal{H}_{x}=0$ and $\mathcal{H}_{c_{c m}}=-\dot{\lambda}$ and transversality condition $\lim _{t \rightarrow \infty} \lambda(t) c_{c m}(t)=0$. These yield the 
equation of motion of the optimal control variable:

$$
\dot{x}(t)=2(r+\mu) x(t)+\left(K e^{-\mu t}+c_{0}-A\right) \mu \sqrt{g} \sqrt{x(t)}
$$

or, in new variable $z(t)=\sqrt{x(t)}$,

$$
\dot{z}=(r+\mu) z+\frac{\mu \sqrt{g}}{2}\left(K e^{-\mu t}+c_{0}-A\right)
$$

Equation (67) has the general solution

$$
z_{c m}(t)=C e^{(r+\mu) t}+\frac{\left(A-c_{0}\right) \mu \sqrt{g}}{2(r+\mu)}-\frac{K \mu \sqrt{g}}{2(r+2 \mu)} e^{-\mu t}
$$

The transversality condition demands boundedness of the optimal solution. Therefore $C=0$ and

$$
z_{c m}(t)=\frac{\left(A-c_{0}\right) \mu \sqrt{g}}{2}\left(\frac{1}{r+\mu}+\frac{\beta e^{-\mu(t-T)}}{(1-2 \beta)(r+2 \mu)}\right)
$$

A.11 Derivation of optimal predation time when $\mu \rightarrow \infty$. First note that $\rho \rightarrow 1$ as $\mu \rightarrow \infty$. Therefore, the feasibility condition $g<4 \rho$ becomes $g<4$ and sustainability condition $g<2 \rho$ becomes $g<2$.

In the case of constrained monopoly, Firm 1's profit from strategic predation becomes

$$
\frac{\left(A-c_{0}\right)^{2}}{4(1-2 \beta)^{2} r g}\left[4\left((1-\beta)^{2} g-1\right)+\left((1-2 \beta)^{2} g^{2}-4(1-\beta)^{2} g+4\right) e^{-r T}\right],
$$

when $\mu \rightarrow \infty$. The coefficient at $e^{-r T}$ is positive if and only if

$$
(1-2 \beta)^{2} g^{2}-4(1-\beta)^{2} g+4>0
$$

We will show that this inequality holds for all $\beta \in\left[0, \frac{1}{2}\right]$ and $g \in[0,2]$. Obviously it holds for $g \leq 1$, since then $(1-2 \beta)^{2} g^{2}-4(1-\beta)^{2} g+4 \geq-4(1-\beta)^{2}+4 \geq 0$. On the other hand, for $g>1$, we rewrite the inequality in an equivalent form $(2-g)^{2}+4 g(2-g) \beta-4 g(1-g) \beta^{2}>0$, which clearly holds when $1<g<2$.

With unconstrained monopoly in the second phase Firm 1's profit from strategic predation becomes

$$
\frac{\left(A-c_{0}\right)^{2}}{(1-2 \beta)^{2} r g}\left[(1-\beta)^{2} g-1+\frac{(2-(1-\beta) g)^{2}}{4-g} e^{-r T}\right]^{2},
$$

when $\mu \rightarrow \infty$. As $g<4$, the coefficient at $e^{-r T}$ is positive. Hence the profit is 
decreasing in $T$.

A.12 Comparison of prices in Section 6.2. First we show that the predation strategy yields a lower price in the predation phase, i.e., for $t \in(0, T]$. Obviously, both prices are the same and equal to $\frac{1}{3}\left(A+2 c_{0}\right)$ at time $t=0$. For $t>0$, both are described by a differential equation of the form (19), or

$$
\dot{p}=\mu\left(\left(B+c_{0}\right)+p(t)-\left(\gamma_{1}+\gamma_{2}\right) \sqrt{g} z(t)\right),
$$

where $z(t)=z_{\text {opt }}(t)$ for the accommodation strategy and $z(t)=z^{u}(T)$ for the predation strategy. According to (58), the latter is higher, yielding a lower price. This is easy to see, when we consider the difference $d$ between the duopoly price and the predation price, which follows the differential equation $\dot{d}=\mu\left[d(t)-\left(\gamma_{1}+\right.\right.$ $\left.\gamma_{2}\right)\left(z_{\text {opt }}(t)-z^{u}(T)\right)$ ], with initial condition $d(0)=0$. Obviously $d(t)>0$, since $\gamma_{1}+\gamma_{2}=\frac{1}{3}(1+\beta)>0$ and $z_{\text {opt }}(t)-z^{u}(T)<0$.

Now it remains to show that for $g \leq 3 \rho /(2-\beta)$, predation yields a lower price in the constrained monopoly phase. Since the price is decreasing in duopoly and increasing in constrained monopoly, it is sufficient to show the inequality for their limits (steady-state values), i.e., that $p^{*} \geq c_{0}$. This is straightforward since substitution of (30) yields an equivalent form $g \leq 3 \rho /(2-\beta)$. 


\section{B Appendix: Figures}

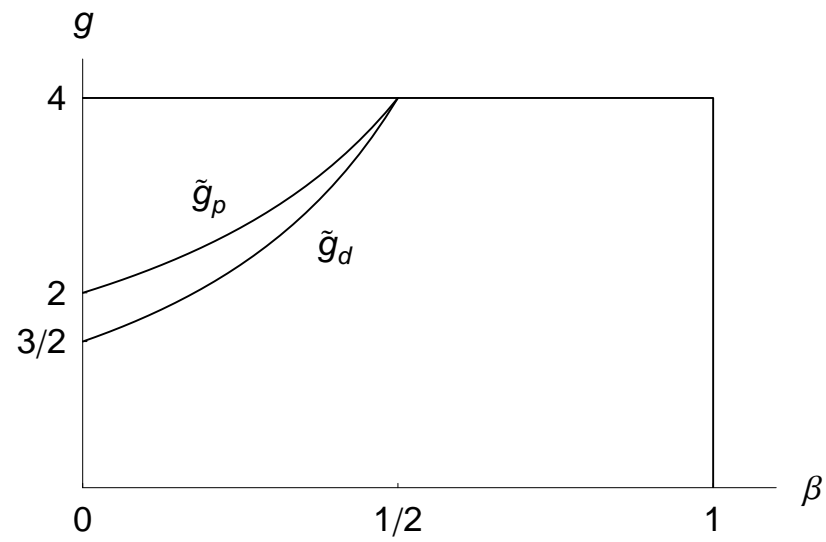

Figure 1: Region of "strategic predation"

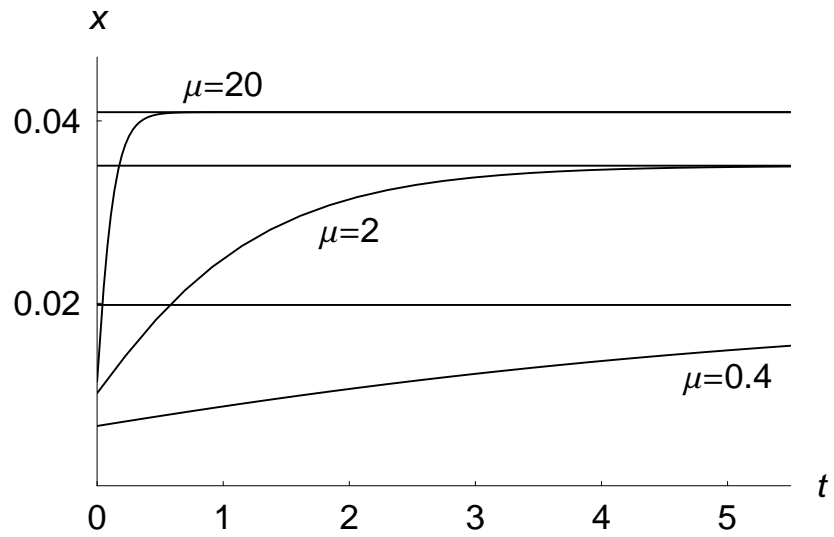

Figure 2: $R \& D$ pattern in duopoly for different values of $\mu: \mu=0.4,2,20$ 


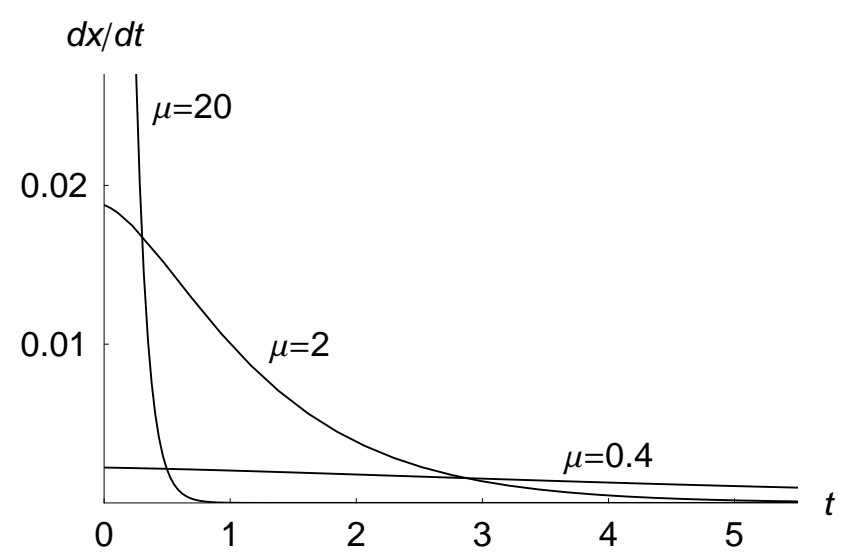

Figure 3: Growth rates of $R \& D$ in duopoly for different values of $\mu: \mu=0.4,2,20$

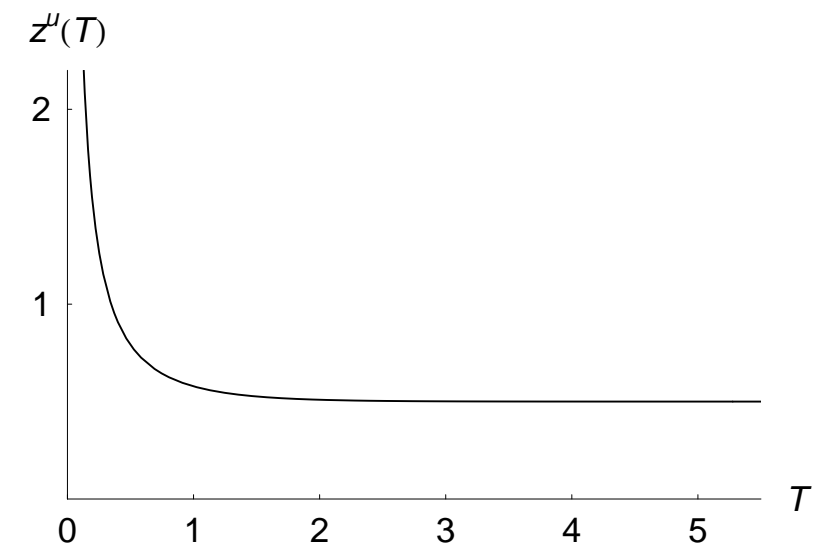

Figure 4: The $z^{u}-T$ schedule 


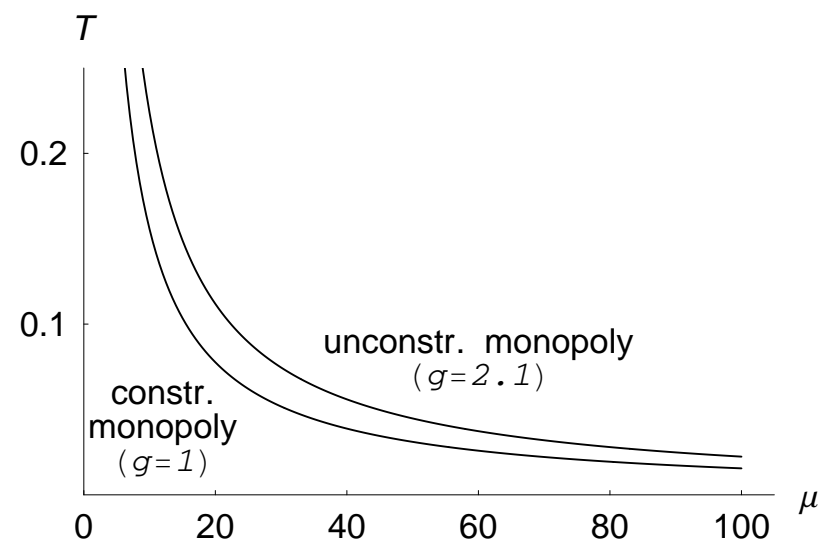

Figure 5: Dependence of the optimal predation time $T$ on $\mu$ in constrained monopoly $(\beta=0.33, g=1)$ and unconstrained monopoly $(\beta=0.33, g=2.1)$

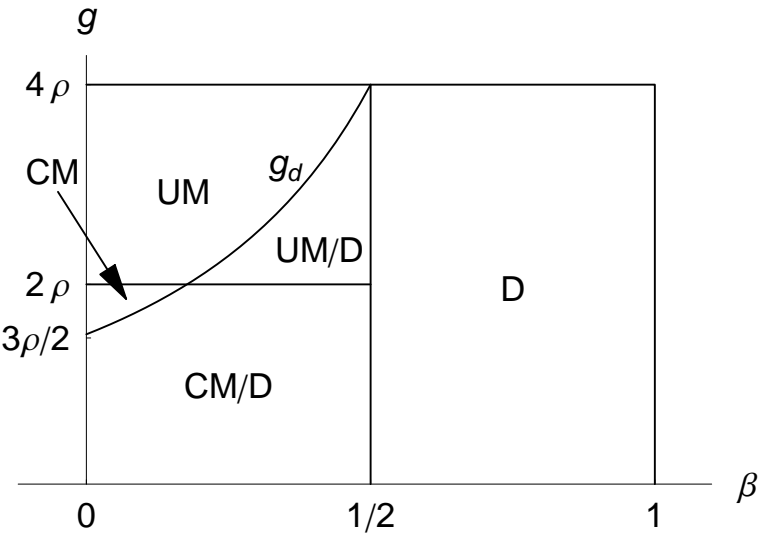

Figure 6: Feasibility and sustainability regions 


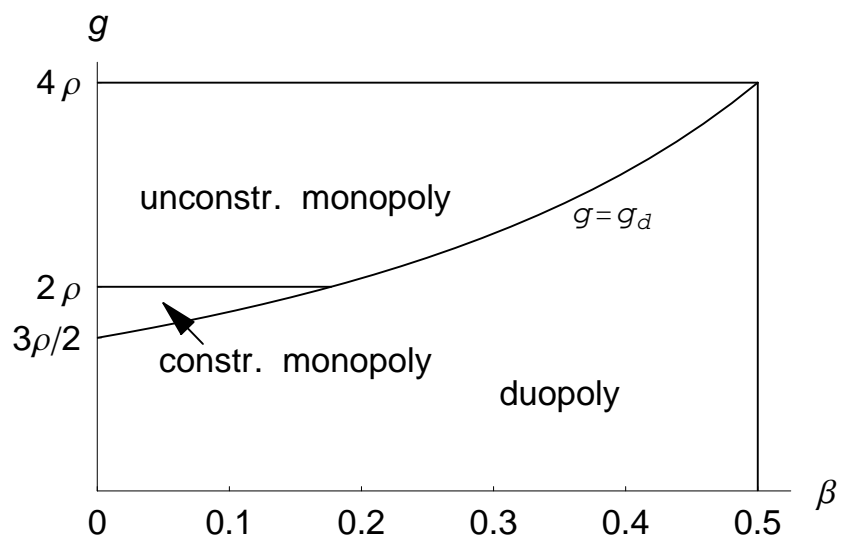

Figure 7: Strategic predation (simulation results for $\mu=0.2$ )

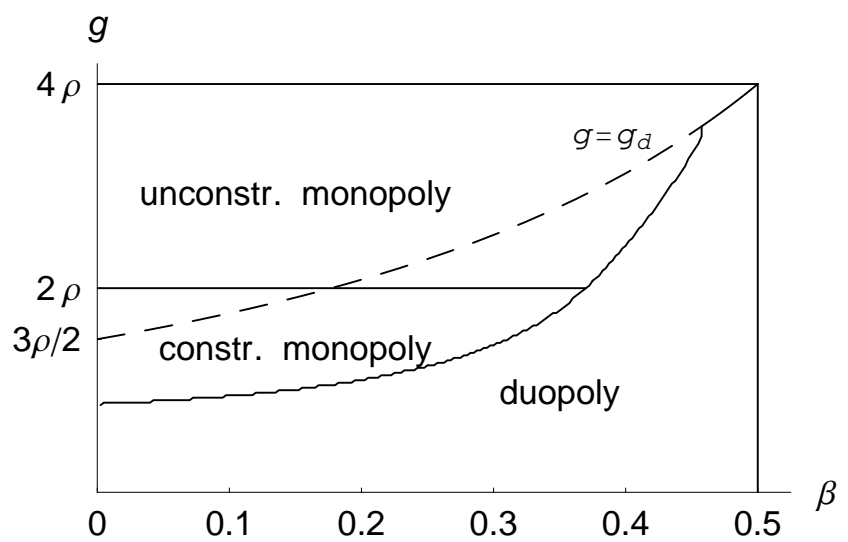

Figure 8: Strategic predation (simulation results for $\mu=2$ ) 


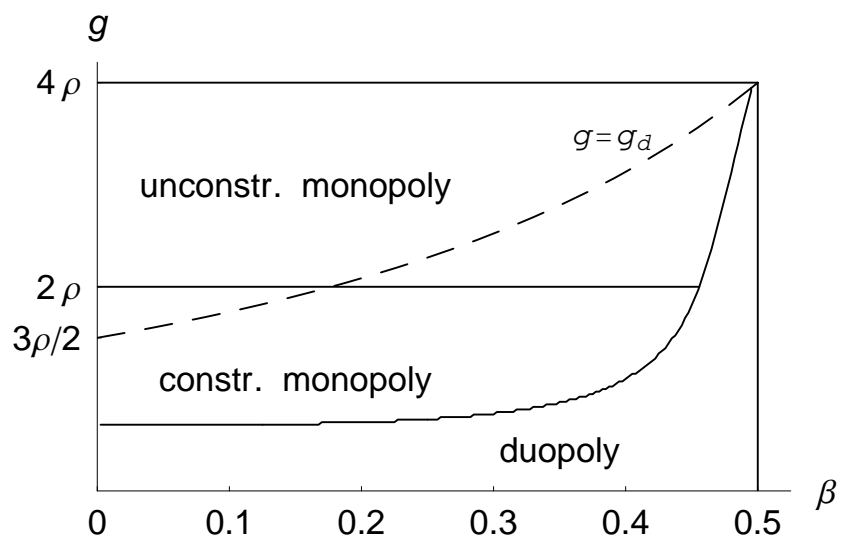

Figure 9: Strategic predation (simulation results for $\mu=20$ )

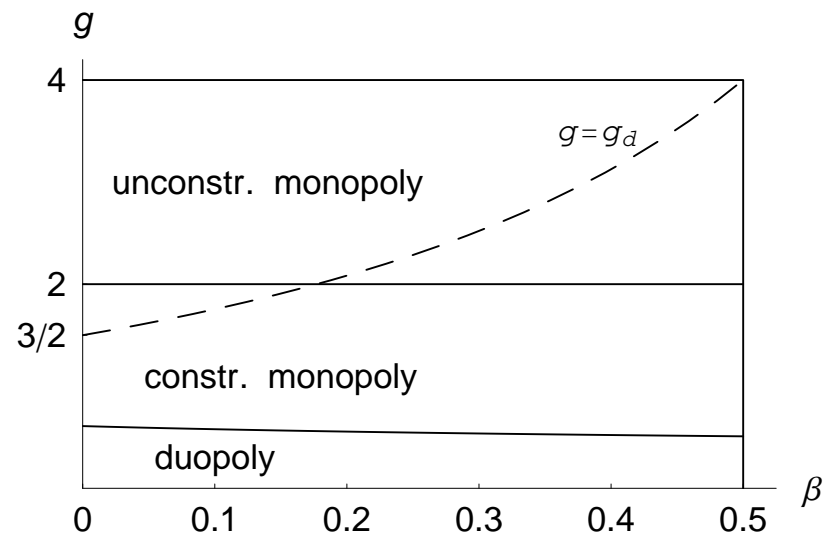

Figure 10: Strategic predation when $\mu \rightarrow \infty$ 


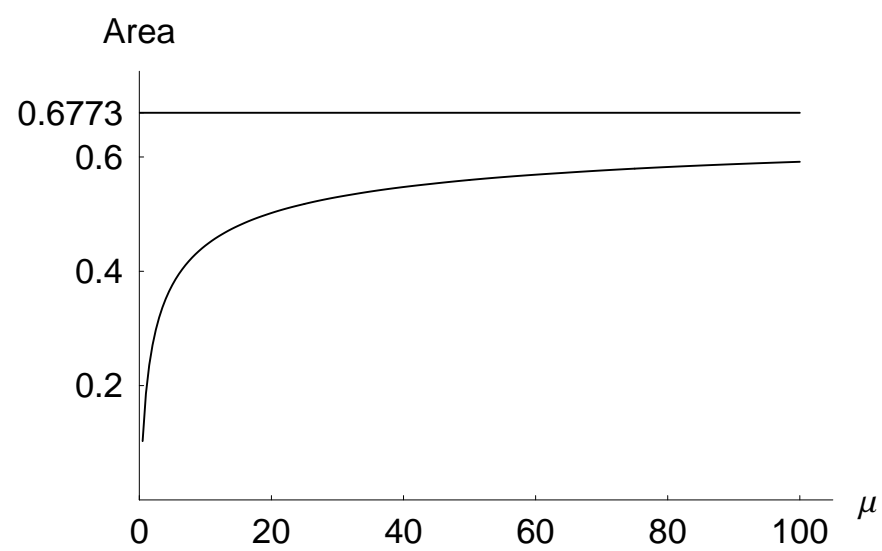

Figure 11: Dependence of area where predation is preferred to duopoly on $\mu$, in region $\mathcal{R}_{c m}$ (simulation results)

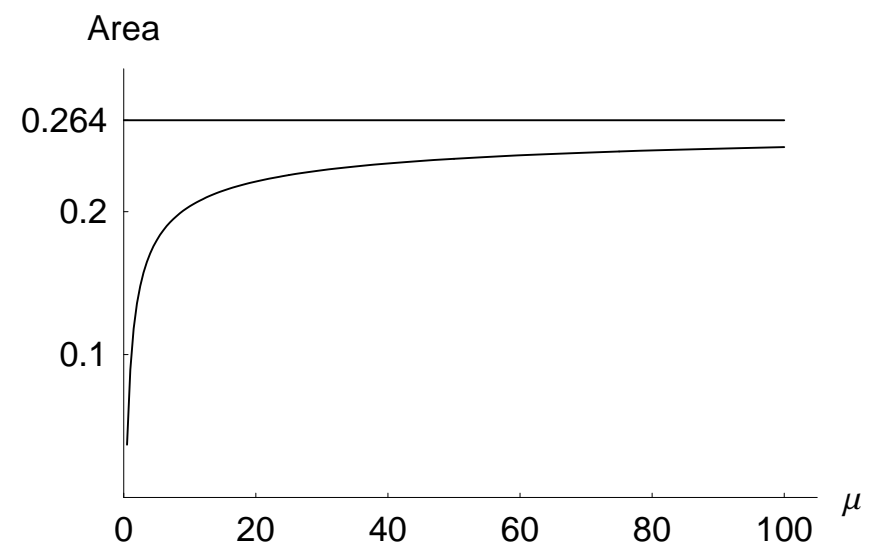

Figure 12: Dependence of area where predation is preferred to duopoly on $\mu$, in region $\mathcal{R}_{m}$ (simulation results) 


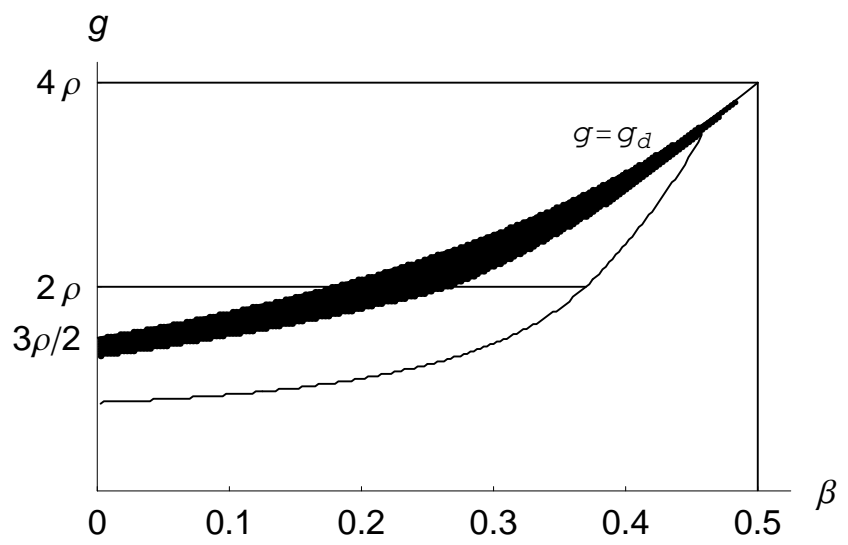

Figure 13: Comparison of present values of $R \& D$ investments (simulation results for $\mu=2$ )

Remark. Here and in all subsequent figures, the shaded area represents the parameters where the corresponding value in accommodation is higher than the value in strategic predation.

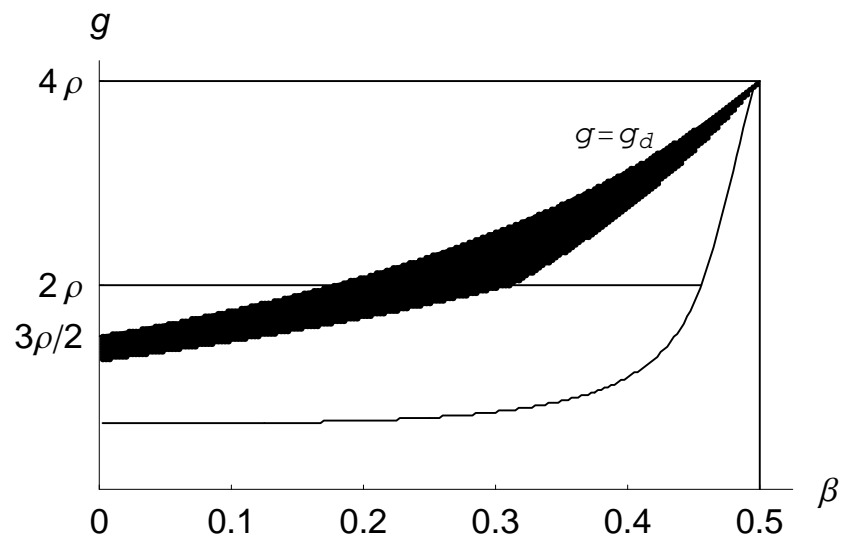

Figure 14: Comparison of present values of $R \& D$ investments (simulation results for $\mu=20)$ 


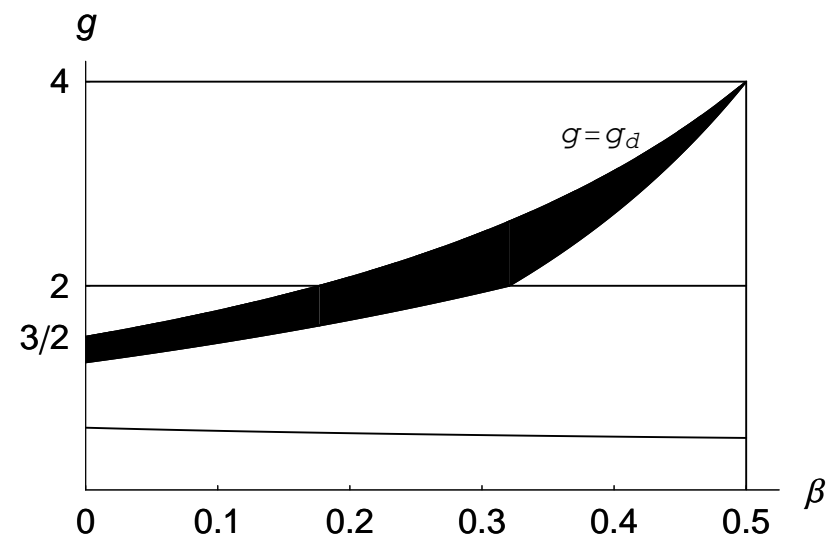

Figure 15: $R \& D$ investment comparison when $\mu \rightarrow \infty$

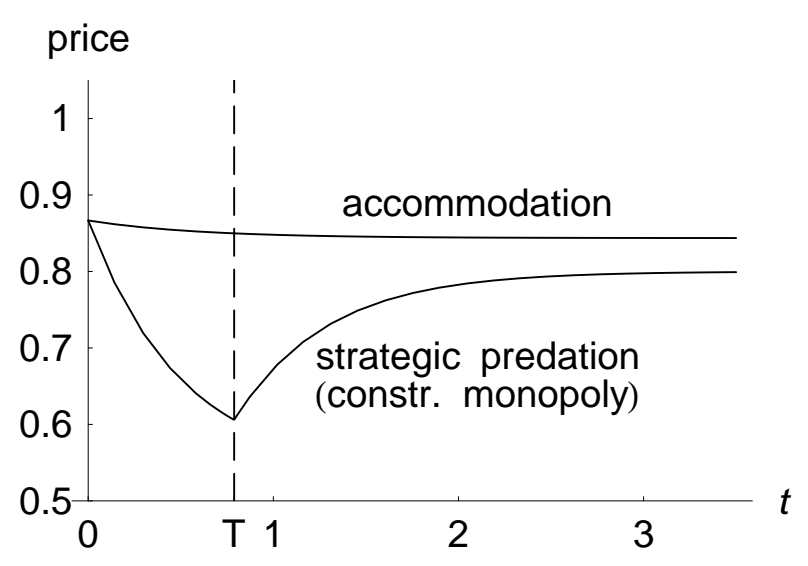

Figure 16: Pattern of price over time with constrained monopoly ( $\mu=2, \beta=0.33$, $g=1)$ 


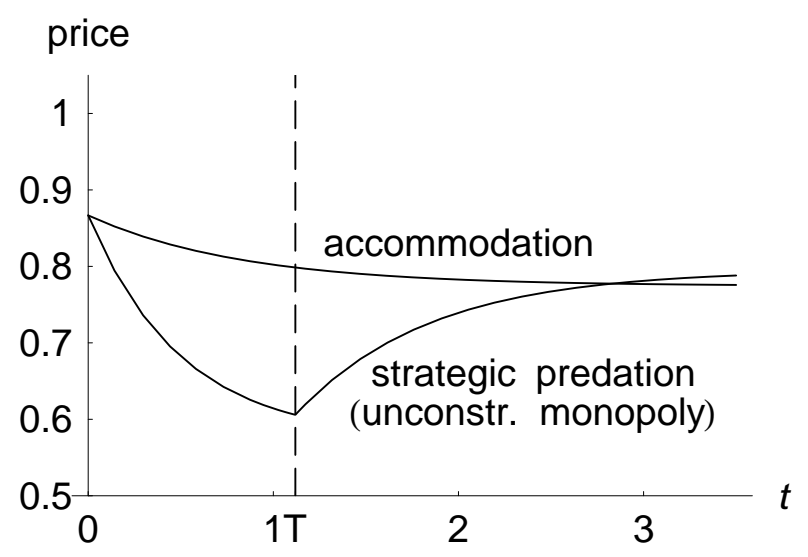

Figure 17: Pattern of price over time with unconstrained monopoly $(\mu=2, \beta=0.33$, $g=2.1)$

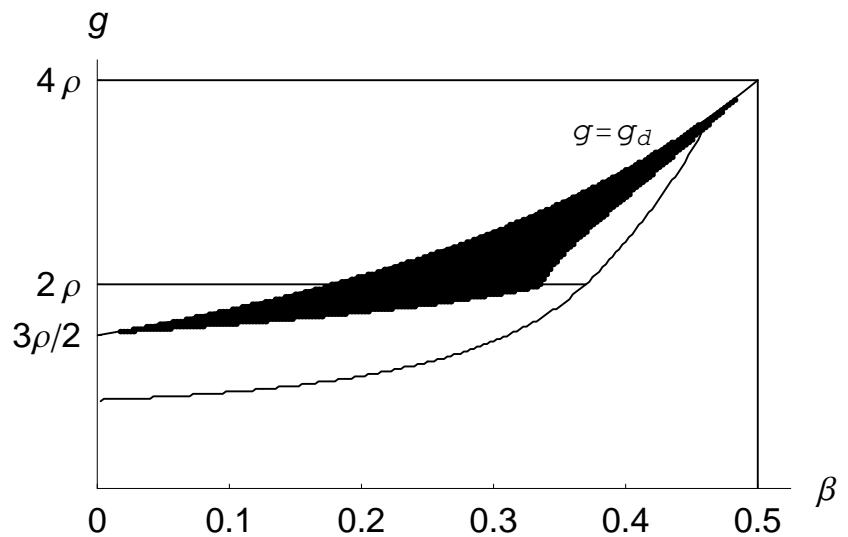

Figure 18: Consumer surplus comparison (simulation results for $\mu=2$ ) 


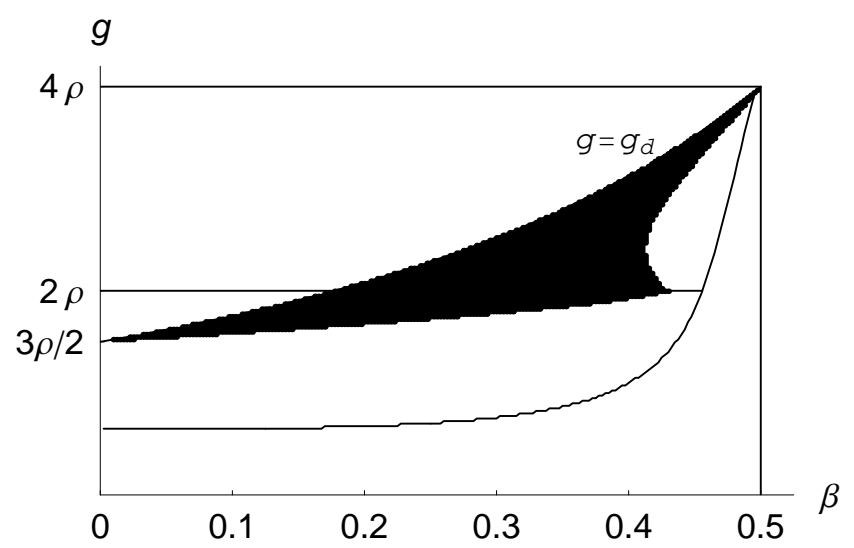

Figure 19: Consumer surplus comparison (simulation results for $\mu=20$ )

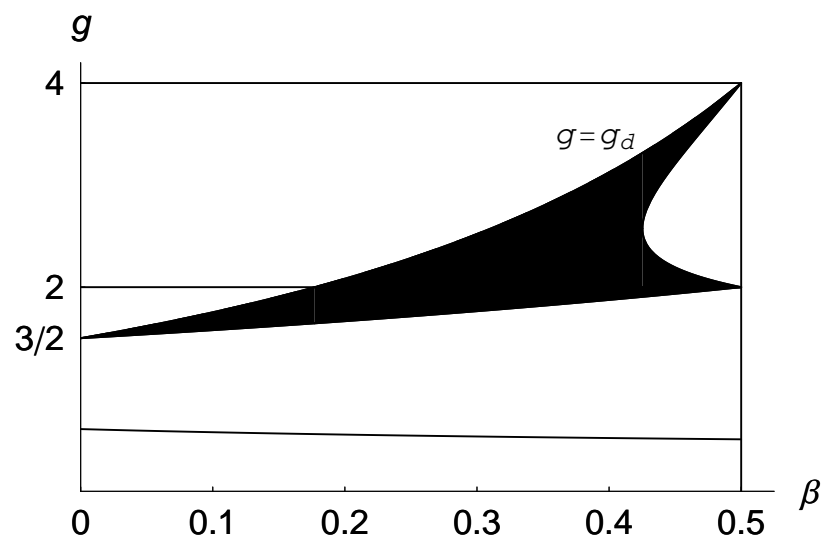

Figure 20: Consumer surplus comparison when $\mu \rightarrow \infty$ 


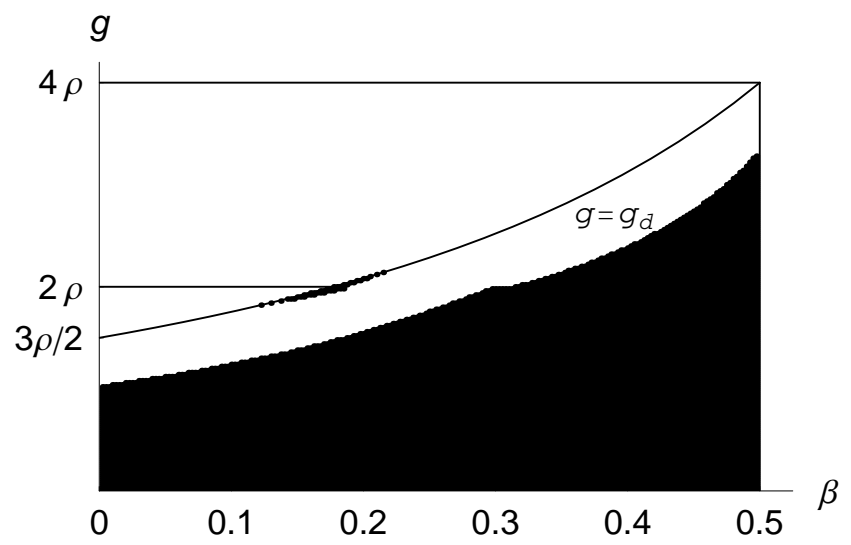

Figure 21: Welfare comparison (simulation results for $\mu=0.2$ )

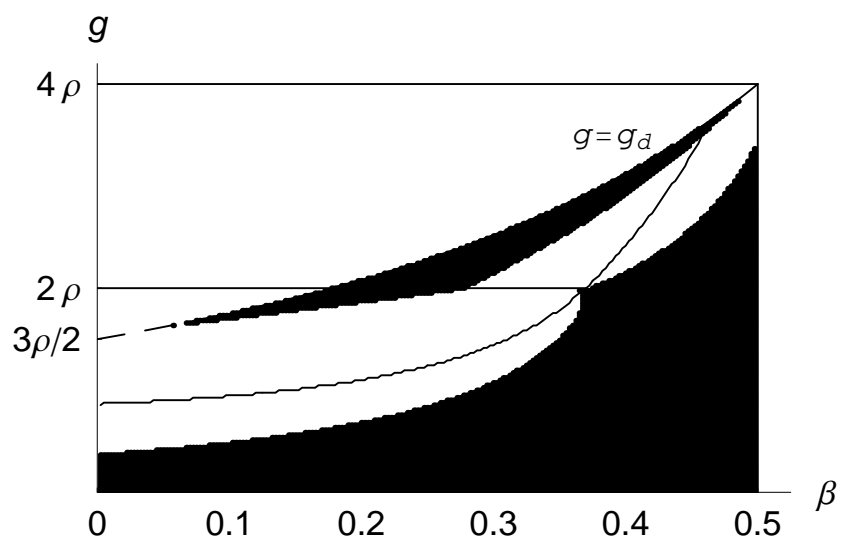

Figure 22: Welfare comparison (simulation results for $\mu=2$ ) 


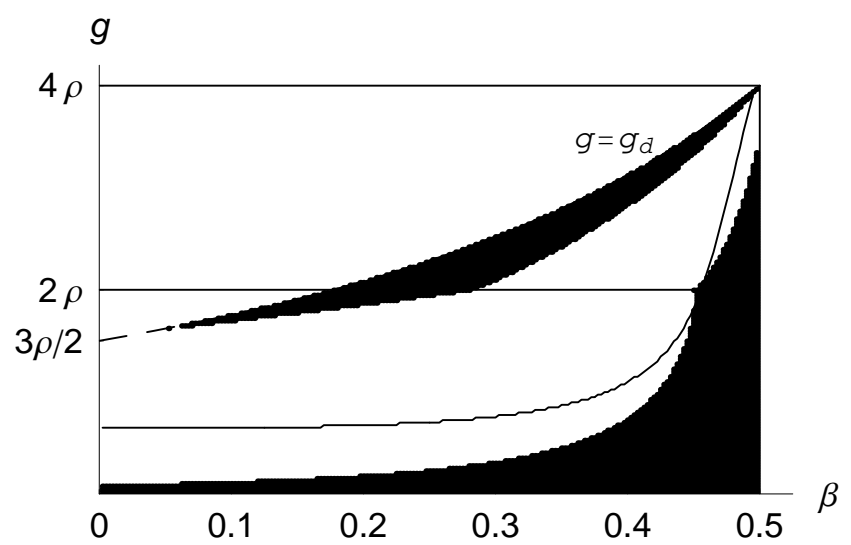

Figure 23: Welfare comparison (simulation results for $\mu=20$ )

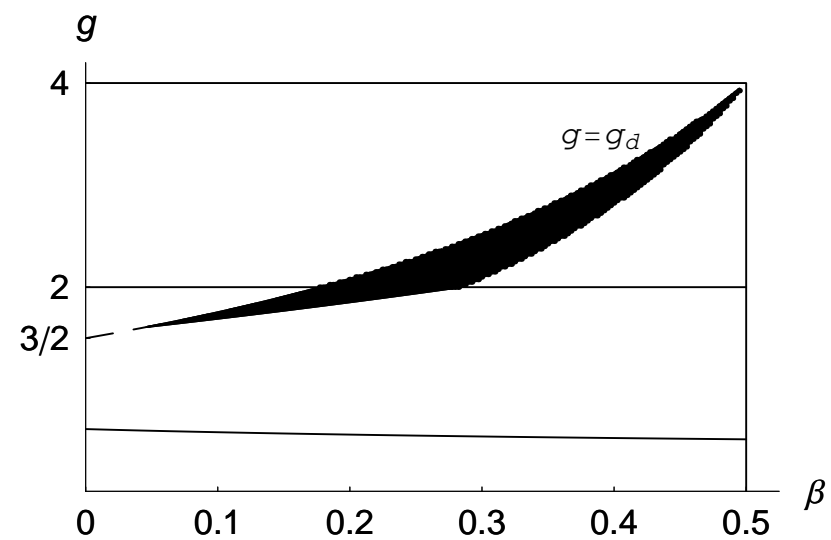

Figure 24: Welfare comparison when $\mu \rightarrow \infty$ (partial simulation results) 


\section{References}

[1] Aghion, P. and R. Griffith (2004). Competition and Growth, Cambridge, MA: The MIT Press.

[2] D'Aspremont, C. and A. Jacquemin (1988). "Cooperative and Noncooperative R\&D in Duopoly with Spillovers," American Economic Review, 78, 113-137.

[3] Baumol, W.J., J.C. Panzar, and R.D. Willig (1982). Contestable Markets and the Theory of Industry Structure, New York: Harcourt Brace Jovanovich, Inc.

[4] Blundell, R., R. Griffin, and J. van Reenen (1999). "Market Share, Market Value and Innovation in a Panel of British Manufacturing Firms," Review of Economic Studies, 66 (3), 529-554.

[5] Bolton, P. and D.S. Scharfstein (1990). "A Theory of Predation Based on Agency Problems in Financial Contracting," American Economic Review, 80 (1), 93-106.

[6] Carlin, W., M.E. Schaffer, and P. Seabright (2004). "A Minimum of Rivalry: Evidence from Transition Economies on the Importance of Competition on Innovation and Growth," CEPR Discussion Paper, No. 4343.

[7] Chin, J.C. and G.M. Grossman (1990). "Intellectual Property Rights and North-South Trade," in R. W. Jones and A. O. Krueger, eds., The Political Economy of International Trade: Essays in Honor of Robert E. Baldwin, Cambridge, MA: Basil Blackwell.

[8] Cohen, W.M. and D.A. Levinthal (1989). "Innovation and Learning: The Two Faces of R\&D," The Economic Journal, 99, 569-596.

[9] Dixit, A. (1979). "A Model of Duopoly Suggesting a Theory of Entry Barriers," The Bell Journal of Economics, 10 (1), 20-32.

[10] Economist (2004). "Slackers or Pace-Setters: Monopolies May Have More Incentives to Innovate than Economists Have Thought," The Economist, May $20,2004$.

[11] Etro, F. (2004). "Innovation by Leaders," The Economic Journal, 114 (485), 281-303. 
[12] Etro, F. (2006a). "Aggressive Leaders," The Rand Journal of Economics, 37, $1-10$.

[13] Etro, F. (2006b). "Industrial Policy: A New Approach," Executive Summary, Available at:

www. intertic.org/Strategic\%20Trade\%20Papers/CompetitionPolicy. pdf.

[14] European Commission (2005). "DG Competition Discussion Paper on the Application of Article 82 of the Treaty to Exclusionary Abuses," Bruxelles.

[15] Fersthman, C. and M. Kamien (1987). "Dynamic Duopolistic Competition with Sticky Prices," Econometrica, 55 (5), 1151-1164.

[16] Griliches, Z. (1992). "The Search for R\&D Spillovers," Scandinavian Journal of Economics, 94, S29-S47.

[17] Haucap, J. and J. Kruse (2002). "Predatory Pricing in Liberalized Telecommunications Market," Universitaet der Bundeswehr Hamburg Discussion Papers in Economic Policy Research, No. 118.

[18] Kobayashi, S. (2001). "A Model of R and D in Oligopoly with Spillovers," Mimeo, Department of Economics, Nihon University, Tokyo, Japan.

[19] McGee, J. (1980). "Predatory Pricing Revisited," Journal of Law and Economics, 23, 289-330.

[20] Nolan, D. (1998). "Predatory Pricing in an Oligopoly Framework," Mimeo, Department of Economics, Royal Holloway University of London.

[21] Ordover, J. and G. Saloner (1989). "Predation, Monopolization, and Antitrust," in R. Schmalensee and R. Willig, eds., Handbook of Industrial Organization, Vol. 1, Ch. 9, Amsterdam: North-Holland.

[22] Rey, P., J.M. Gual, M. Hellwig, A. Perrot, M. Polo, K. Schmidt, and R. Stenbacka (2005). "An Economic Analysis to Article 82," Report of the Economic Advisory Group for Competition Policy, European Union.

[23] Scherrer, F.M. and D. Ross (1990). Industrial Market Structure and Economic Performance, 3rd edition, Boston: Houghton Mifflin Company.

[24] Shapiro, C. (1989). "Theories of Oligopoly Behaviour," in R. Schmalensee and R. Willig, eds., Handbook of Industrial Organization, pp. 329-410, Amsterdam: North-Holland. 
[25] Stenbacka, R. and M.M. Tombak (1993). "Commitment and Efficiency in Reach Joint Ventures," Mimeo.

[26] Telser, L. (1966). "Cutthroat Competition and Long Purse," Journal of Law and Economics, 9, 259-277.

[27] Tirole, J. (1991). The Theory of Industrial Organization, Cambridge, MA: The MIT Press.

[28] Vinogradov, V. and K. Žigič (1999). "R\&D Spillovers in Duopoly: Static versus Dynamic Models," CERGE-EI Discussion Paper, No. 1999-34.

[29] Wiethaus, L. (2005). "Excess Absorptive Capacity and the Persistence of Monopoly," paper presented at 6. Symposium zur Ökonomischen Analyse der Unternehmung, also available at: www.intertic.org/Theory/Intertic-theory.htm.

[30] Žigič, K. (1998). "Intellectual Property Rights Violations and Spillovers in North-South Trade," European Economic Review 42, 1779-1799.

[31] Žigič, K. (2000). "Strategic Trade Policy, Intellectual Property Rights Protection, and North-South Trade," Journal of Development Economics, 61, 27-60. 
Individual researchers, as well as the on-line and printed versions of the CERGE-EI Working Papers (including their dissemination) were supported from the following institutional grants:

- Economic Aspects of EU and EMU Entry [Ekonomické aspekty vstupu do Evropské unie a Evropské měnové unie], No. AVOZ70850503, (2005-2010);

- Economic Impact of European Integration on the Czech Republic [Ekonomické dopady evropské integrace na ČR], No. MSM0021620846, (2005-2011);

Specific research support and/or other grants the researchers/publications benefited from are acknowledged at the beginning of the Paper.

(c) Eugen Kováč, Viatcheslav Vinogradov, Krešimir Žigič, 2007.

All rights reserved. No part of this publication may be reproduced, stored in a retrieval system or transmitted in any form or by any means, electronic, mechanical or photocopying, recording, or otherwise without the prior permission of the publisher.

Published by

Charles University in Prague, Center for Economic Research and Graduate Education (CERGE) and

Economics Institute ASCR, v.v.i. (EI)

CERGE-El, Politických vězñů 7, 11121 Prague 1, tel.: +420 224005 153, Czech Republic.

Printed by CERGE-EI, Prague

Subscription: CERGE-EI homepage: http://www.cerge-ei.cz

Editors: Directors of CERGE and EI

Managing editors: Deputy Directors for Research of CERGE and EI

ISSN 1211-3298

ISBN 978-80-7343-113-6 (Univerzita Karlova. Centrum pro ekonomický výzkum

a doktorské studium)

ISBN 978-80-7344-102-9 (Národohospodářský ústav AV ČR, v.v.i.) 
CERGE-EI

P.O.BOX 882

Politických vězňů 7

11121 Praha 1

Czech Republic http://www.cerge-ei.cz 